\title{
Genome-wide analyses reveal the IRE1a-XBP1 pathway promotes $T$ helper cell differentiation by resolving secretory stress and accelerating proliferation
}

Jhuma Pramanik1, Xi Chen', Gozde Kar1,2, Johan Henriksson'1, Tomás Gomes', Jong-Eun Park', Kedar Natarajan', Kerstin B. Meyer', Zhichao Miao ${ }^{1,2}$, Andrew N. J. McKenzie ${ }^{3}$, Bidesh Mahata ${ }^{1,2^{*}}$ and Sarah A. Teichmann $n^{1,2,4^{*}}$

\begin{abstract}
Background: The IRE1a-XBP1 pathway is a conserved adaptive mediator of the unfolded protein response. The pathway is indispensable for the development of secretory cells by facilitating protein folding and enhancing secretory capacity. In the immune system, it is known to function in dendritic cells, plasma cells, and eosinophil development and differentiation, while its role in Thelper cell is unexplored. Here, we investigated the role of the IRE1a-XBP1 pathway in regulating activation and differentiation of type-2 $T$ helper cell (Th2), a major T helper cell type involved in allergy, asthma, helminth infection, pregnancy, and tumor immunosuppression.
\end{abstract}

Methods: We perturbed the IRE1a-XBP1 pathway and interrogated its role in Th2 cell differentiation. We performed genome-wide transcriptomic analysis of differential gene expression to reveal IRE1a-XBP1 pathway-regulated genes and predict their biological role. To identify direct target genes of XBP1 and define XBP1's regulatory network, we performed XBP1 ChIPmentation (ChIP-seq). We validated our predictions by flow cytometry, ELISA, and qPCR. We also used a fluorescent ubiquitin cell cycle indicator mouse to demonstrate the role of XBP1 in the cell cycle.

Results: We show that Th2 lymphocytes induce the IRE1a-XBP1 pathway during in vitro and in vivo activation. Genome-wide transcriptomic analysis of differential gene expression by perturbing the IRE1a-XBP1 pathway reveals XBP1-controlled genes and biological pathways. Performing XBP1 ChIPmentation (ChIP-seq) and integrating with transcriptomic data, we identify XBP1-controlled direct target genes and its transcriptional regulatory network. We observed that the IRE1a-XBP1 pathway controls cytokine secretion and the expression of two Th2 signature cytokines, IL13 and IL5. We also discovered that the IRE1a-XBP1 pathway facilitates activation-dependent Th2 cell proliferation by facilitating cell cycle progression through $\mathrm{S}$ and G2/M phase.

Conclusions: We confirm and detail the critical role of the IRE1a-XBP1 pathway during Th2 lymphocyte activation in regulating cytokine expression, secretion, and cell proliferation. Our high-quality genome-wide XBP1 ChIP and gene expression data provide a rich resource for investigating XBP1-regulated genes. We provide a browsable online database available at http://data.teichlab.org.

Keywords: IRE1a-XBP1 pathway, IRE1a, XBP1, T helper cell activation, Genome-wide XBP1 chromatin occupancy, Th2 lymphocyte proliferation, XBP1 ChIP-seq, RNA-seq, Th2 transcriptome

\footnotetext{
*Correspondence: bm11@sanger.ac.uk; st9@sanger.ac.uk

'Wellcome Sanger Institute, Wellcome Genome Campus, Hinxton, Cambridge CB10 1SA, UK

Full list of author information is available at the end of the article
}

(c) The Author(s). 2018 Open Access This article is distributed under the terms of the Creative Commons Attribution 4.0 International License (http://creativecommons.org/licenses/by/4.0/), which permits unrestricted use, distribution, and reproduction in any medium, provided you give appropriate credit to the original author(s) and the source, provide a link to the Creative Commons license, and indicate if changes were made. The Creative Commons Public Domain Dedication waiver (http://creativecommons.org/publicdomain/zero/1.0/) applies to the data made available in this article, unless otherwise stated. 


\section{Background}

$\mathrm{T}$ helper ( $\mathrm{Th}$ ) cells $\left(\mathrm{CD} 4^{+} \mathrm{T}\right.$ cells) are central to the adaptive immune response and immune tolerance and potentiate innate immune response pathways [1, 2]. These cells are key players in infections, allergies, auto-immunity, and anti-tumor immune responses. Depending upon the immunogen or allergen (e.g., infection, commensal microorganism, or self-antigen), naive $\mathrm{T}$ helper cells become activated, proliferate, and are able to differentiate into several subtypes, such as Th1, Th2, Th17, and regulatory $\mathrm{T}$ cell (Treg). This Th subtype classification is based on their differential expression of cytokines and key lineage-specific transcription factors [2, 3]. Th2 lymphocytes secrete the characteristic cytokines IL4, IL5, IL10, and IL13. These secretory cells are involved in worm parasite expulsion, exaggerate allergies and asthma, potentiate pregnancy [4], and suppress anti-tumor immunity [5]. Transcription factors that are involved in differential production and regulation of cytokine genes, for example GATA3 in Th2, are well studied. However, cytokine gene expression is only one aspect of the $\mathrm{T}$ helper cell differentiation process. The ability to rapidly proliferate is another key attribute of $\mathrm{T}$ helper lymphocytes (Fig. 1a), and the full regulatory circuitry controlling these processes is still incompletely understood.

Proliferation is required for clonal expansion, which forms the basis of the adaptive immune response [6, 7]. The Gata3/RuvB-like protein 2 (Ruvbl2) complex was shown to be a key regulator of Th2 cell proliferation [8], and several other transcription factors, such as Stat6, are implicated in the regulatory circuitry controlling $\mathrm{T}$ helper cell proliferation and differentiation. Additional transcription factors are likely to be involved in regulating this highly organized, complex process.

At the cell biological level, to synthesize, fold, and secrete proteins, including cytokines, activated $\mathrm{T}$ helper cells need to contain a well-differentiated endoplasmic reticulum (ER) and protein secretory machinery. It is an open question how activated $\mathrm{T}$ helper cells meet this protein folding and secretory demand. Secretory cells (e.g., pancreatic $\beta$-cell, acinar cells) address this challenge by upregulating the unfolded protein response (UPR) pathway triggered by the accumulation of unfolded proteins in the endoplasmic reticulum (ER) [9-11]. Three ER membrane-resident sensors, the endonuclease IRE1a (encoded by ERN1 gene), the kinase PERK, and the cleavable precursor of the transcription factor ATF6, coordinate the process. Among these three, the IRE1a-XBP1 pathway is the most evolutionary conserved pathway (Fig. 1a) $[12,13]$. During ER stress, the kinase, IRE1a, oligomerizes, autophosphorylates, and uses its endoribonuclease activity to splice a 26-nucleotide fragment from the unspliced XBP1 mRNA (XBP1u). This then results in the functional spliced form of the transcription factor XBP1 (XBP1s) [14]. XBP1s regulates the expression of numerous target genes involved in ER biogenesis. Its role has been studied in secretory cells, such as pancreatic acinar cells, plasma cells, and dendritic cells (DCs). In these cell types, XBP1 occupies chromatin and controls gene expression in a cell-type-specific manner [15]. This suggests that XBP1 may play a role in diverse cell types. Therefore, we set out to investigate its specific function in $\mathrm{CD}^{+} \mathrm{T}$ lymphocytes (Fig. 1a).

The role of the IRE1a-XBP1 pathway in immunity and inflammation is now emerging [16-20]. The pathway has been described in dendritic cells, plasma cells, $\mathrm{CD}^{+}$ $\mathrm{T}$ cells, and eosinophil development and differentiation [21-26]. Interestingly, it has been reported recently that the pathway causes cancer-associated immune suppression by causing dendritic cell dysfunction [27]. The pathway is also involved in alternative activation of macrophages and in obesity [28]. Together, these reports suggest that the XBP1 transcription factor can contribute to a wide range of biological processes. IRE1a inhibitors (e.g., $4 \mu 8 \mathrm{c}$ ) have been proposed as a treatment of cancer, by reinstating cancer immunity and eosinophilia by inhibiting eosinophil differentiation [21, 27, 29, 30]. Here, we test the role of the XBP1 transcription factor in regulating $\mathrm{T}$ helper cell activation through inhibition of the IRE1a-XBP1 pathway by the small molecule inhibitor $4 \mu 8 \mathrm{c}$.

Using genome-wide approaches, integrating transcriptomic and XBP1 chromatin occupancy data, we elucidate the regulatory circuitry governed by the IRE1a-XBP1 pathway in Th2 lymphocytes. We found that the pathway observed in other cells is conserved in T helper cells in terms of secretory stress adaptation. Further, we show that XBP1 regulates genes that control diverse facets of Th2 cell physiology. In addition to resolving protein folding and secretory stress, it accelerates cell proliferation and controls cytokine synthesis and secretion.

Our data provide a rich resource for investigating XBP1-regulated genes with genome-wide chromatin occupancy and expression, with a browsable online database at http://data.teichlab.org.

\section{Methods \\ Materials}

$\mathrm{CD}^{+} \mathrm{CD}^{2} \mathrm{~L}^{+} \mathrm{T}$ Cell Isolation Kit II, mouse (Miltenyi Biotec, 130-093-227); Naive CD4. ${ }^{+}$T Cell Isolation Kit, mouse (Miltenyi Biotec, 130-104-453); FITC BrdU Flow Kit (BD Pharmingen, 51-2354AK); LIVE/DEAD ${ }^{\text {тм }}$ Fixable Violet Dead Cell Stain Kit (Molecular probes, L34955); CellTrace $^{\mathrm{TM}}$ Violet Cell Proliferation Kit (Molecular probes, C34571); Mouse IL-13 ELISA Ready-SET-Go Kit (eBioscience, 88-7137-22); Mouse IL-4 ELISA Ready-SETGo Kit (eBioscience, 88-7044-88); Mouse IL-5 ELISA (BD 


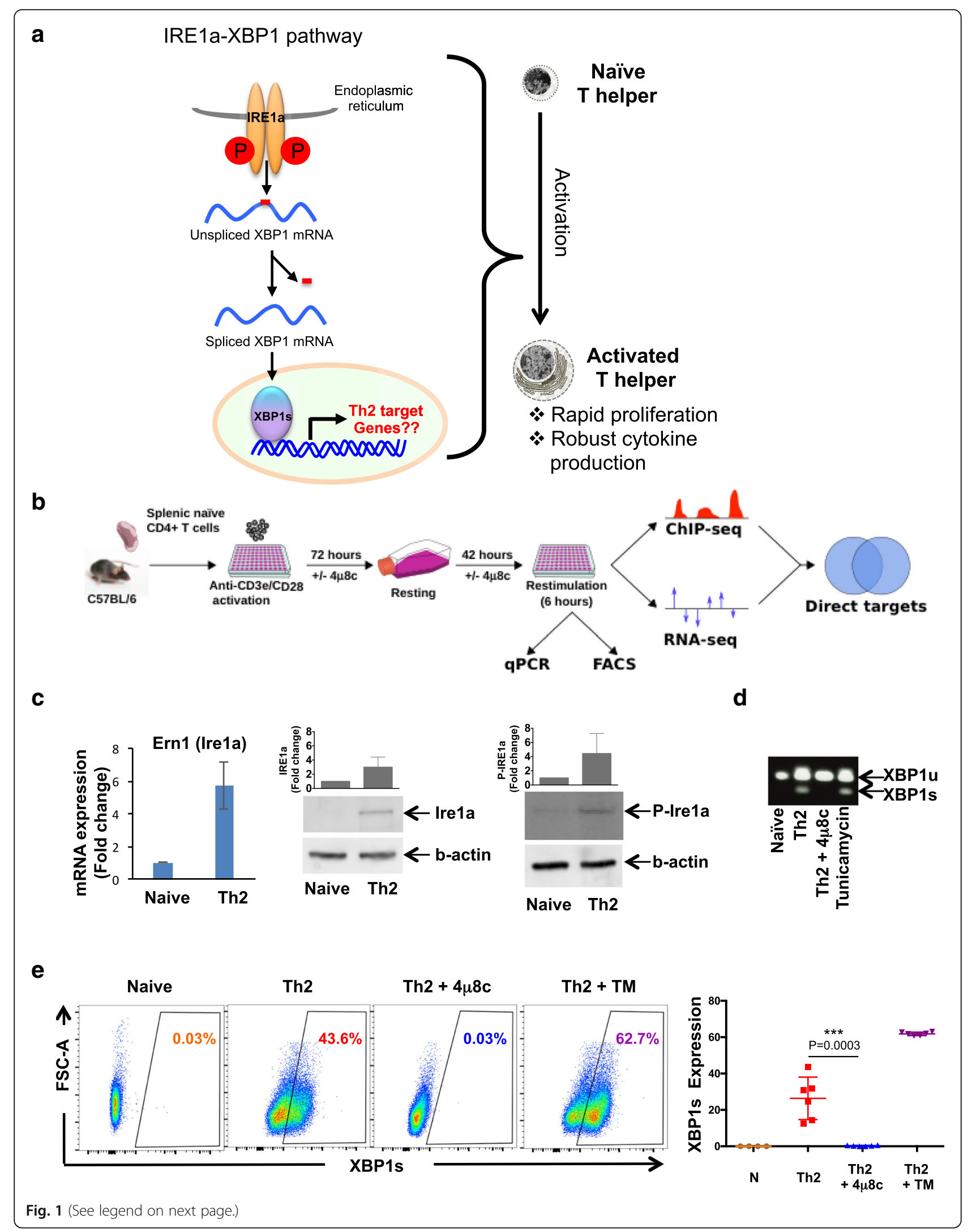


(See figure on previous page.)

Fig. $1 \mathrm{~T}$ helper cells upregulate the IRE1a-XBP1 pathway during activation. a Schematic representation of the hypothesis. In this study, we are asking what role does the IRE1a-XBP1 pathway play during T helper cell activation. Thelper cell activation is a dramatic transformation from a quiescent cell state to a rapidly proliferative and highly protein productive/secretive cellular state. $\mathbf{b}$ Overview of the experiment. Splenic naïve $T$ cells were purified by negative selection and activated in anti-CD3e/C28 antibody-coated plates under Th2 differentiation conditions (i.e., in the presence of anti-IFNy neutralizing antibody, IL2, and IL4) for $72 \mathrm{~h}$, rested for $42 \mathrm{~h}$, and restimulated on anti-CD3e/CD28 antibody-Coated plate. Restimulated Th2 cells were used in RNA sequencing, ChIPmentation (ChIP sequencing), Western blot, qPCR, and flow cytometry. To perturb IRE1a-XBP1 pathway, we used 15- $\mu \mathrm{M} 4 \mu 8 \mathrm{c}$ that specifically blocks the pathway by inhibiting IRE1a endonuclease activity. The drug was added to the culture media at the beginning of the culture and during passage from the activation plate to the resting plate. $\mathbf{c}$ Naïve T helper cells and in vitro differentiated Th2 lymphocytes were analyzed for IRE1 a mRNA expression by qRT-PCR (left panel), protein expression by Western blot (middle panel), and phosphorylated IRE1a (P-IRE1a) by Western blot (right panel). The density of Western blot bands from five independent experiments of IRE1a and three independent experiments of phospho-IRE1a were measured and displayed on top of each Western blot panel. d Naïve T cells were cultured under Th2 differentiation conditions in the presence or absence of IRE1a inhibitor (4 $48 \mathrm{c})$. In vitro reactivated Th2 lymphocytes were analyzed by RT-PCR using a pair of primers that discriminate the CDNA derived from spliced and unspliced form of XBP1 mRNA. Tunicamycin-treated Th2 cells were used as a positive control. e Naïve Thelper cells $(\mathrm{N})$ and in vitro differentiated and restimulated Th2 cells (differentiated in the presence or absence of $4 \mu 8 \mathrm{c}$ ) were stained with fluorescent dye-conjugated anti-XBP1s-specific antibody and analyzed by flow cytometry. Gating: singlets > live cells > XBP1s. One representative FACS profile is displayed (left panel), and the graph containing all results $(n=5)$ is shown in the "right panel". Tunicamycin-treated Th2 cells were used as a positive control

Biosciences, 555236); PE Mouse anti-XBP1S Clone Q3-695 (BD Pharmingen, 562642); XBP1 (M-186)X(Santa cruz, Sc 7160x); IL5-PE (BD Pharmingen, 554395); IL4-APC, Clone 11B11 (eBioscience, 17-7041-82); IL13AF488, Clone eBio3A (eBioscience, 53-7133-82); IFN $\gamma$-Per CP Cy5.5, Clone XMG1.2 (eBioscience, 45-7311-82); FACS Staining buffer (eBioscience, 00-4222-26); IC Fixation buffer (eBioscience, 00-8222-49); Fixation/ Permeabilization Diluent (eBioscience, 00-5223-56); Fixation/Permeabilization concentrate (eBioscience, 005123-43); Permeabilization buffer (eBioscience, 00-833356); SV Total RNA Isolation System (Promega, Z3101); Transcriptor High Fidelity cDNA Synthesis kit (Roche, 05081955001); SYBR ${ }^{\mathrm{mm}}$ Select Master Mix (Applied Biosystems, 4472908); Western blot antibodies: IRE1 $\alpha$ (14C10) Rabbit mAb (Cell Signaling, \#3294), IRE1 alpha [p Ser724] Antibody (Novus biologicals,NB100-2323).

\section{Mice}

The mice (C57BL/6, IL13-eGFP reporter, IL4-eGFP reporter, and FUCCI) were maintained under specific pathogen-free conditions at the Wellcome Trust Genome Campus Research Support Facility (Cambridge, UK) and were used at 6-12 weeks of age. We generated a transgenic FUCCI mouse, similar to published FUCCI strain [31].

\section{T helper cell culture}

Splenic naive $\mathrm{T}$ helper cells were purified with the CD ${ }^{+}{ }^{C D} 62 L^{+} \mathrm{T}$ Cell Isolation Kit II (Miltenyi Biotec) and polarized in vitro toward differentiated Th2 subtype as described before in [32]. In brief, naive cells were seeded into anti-CD3e $(2 \mu \mathrm{g} / \mathrm{ml}$, clone $145-2 \mathrm{C} 11$, eBioscience) and anti-CD28 (5 $\mu \mathrm{g} / \mathrm{ml}$, clone 37.51, eBioscience) antibody coated 96-well round bottom plates. The medium contained the following cytokines and/or antibodies for Th2 subtype: recombinant murine
IL-2 (10 ng/ml, R\&D Systems), recombinant murine IL-4 (10 ng/ml, R\&D Systems), and neutralizing anti-IFN-g (5 $\mu \mathrm{g} / \mathrm{ml}$, cloneXMG1.2eBioscience). The cells were removed from the activation plate on day 4 (72 h). Th2 cells were cultured for another 2 days in the absence of anti-CD3 and CD28 stimulation. Then, cells were restimulated by anti-CD3e/CD28-coated plate for 6 h. For flow cytometric detection, cells were treated with monensin ( $2 \mu \mathrm{M}$, eBioscience) for the last $3 \mathrm{~h}$.

\section{$4 \mu 8 \mathrm{c}$ treatment}

$4 \mu 8 \mathrm{c}$ (final concentration $15 \mu \mathrm{M}$ ) was added to the culture media at the beginning of the culture, and with the fresh culture media when cells were transferred from the activation plate to the resting plate.

\section{Reverse transcription quantitative PCR (RT-qPCR)}

Total RNA was isolated from two million cells by SV total RNA isolation kit (Promega). cDNA was prepared by annealing 500 ng RNA with oligo dT as per the manufacturer's instructions (Transcriptor High Fidelity cDNA Synthesis kit, Roche). The cDNA samples were diluted 10 times with $\mathrm{H} 20$. Two microliters of cDNA was used in $12 \mu \mathrm{l}$ qPCR reactions with appropriate primers and SYBR Green PCR Master Mix (Applied Biosystems). Experiments were performed at least three times and data represent mean values \pm standard deviation. For XBP1, mRNA was amplified by PCR and products were separated by electrophoresis through a $2.5 \%$ agarose gel and visualized by ethidium bromide staining. The primer list is provided below:

\section{IL4-F: 5' -AACTCCATGCTTGAAGAAGAACTC-3' IL4-R: 5' -CCAGGAAGTCTTTCAGTGATGTG-3' \\ IL13-F: 5' -CCTGGCTCTTGCTTGCCTT-3' \\ IL13-R: 5' -GGTCTTGTGTGATGTTGCTCA-3' \\ IL5-F: 5' -GCAATGAGACGATGAGGCTTC-3'}


IL5-R: 5'-CCCCTGAAAGATTTCTCCAATG-3' ERN1-F: 5' -ACACCGACCACCGTATCTCA-3' ERN1-R: 5'-CTCAGGATAATGGTAGCCATGTC-3' XBP1-F: 5' -ACACGCTTGGGAATGGACAC-3' XBP1-R: 5' -CCATGGGAAGATGTTCTGGG-3' RPLP0-F: 5'-CACTGGTCTAGGACCCGAGAA-3' RPLP0-R: 5' -GGTGCCTCTGGAGATTTTCG-3' XBP1s-F: 5' -ACACGCTTGGGAATGGACAC-3' XBP1s-R: 5'-GTGTCAGAGTCCATGGGA-3'

\section{ELISA}

IL13, IL4, and IL5 concentration in the Th2 culture supernatants were quantified using ELISA kit following the manufacturer's instruction (see the "Materials" section for the kit specification).

\section{Flow cytometry}

In worm infection mouse experiments, splenocytes were prepared on day 7 post-infection from Nippostrongylus brasiliensis infected or control uninfected mice, stained with anti-CD3e, anti-CD4 (eBioscience), and XBP1s-PE (BD Pharmingen) antibodies following the mouse regulatory $\mathrm{T}$ cell staining kit protocol (eBioscience), and were measured by flow cytometry on a Fortessa (BD Biosciences) using FACSDiva. The data were analyzed by the FlowJo software. For in vitro Th cell experiments, staining was performed following eBioscience intracellular staining protocol for cytokines and nuclear staining/ transcription factor staining protocol for XBP1 transcription factor using eBioscience reagents and kit protocol. The following antibodies were fluorescent dye-conjugated primary antibodies: IL-4, IL-13, IL-5, CD4 and IFNY (eBioscience), and XBP1s (BD Pharmingen). Stained cells were analyzed on a Fortessa (BD Biosciences) using FACSDiva and FlowJo software. CompBeads (BD Biosciences) were used for compensation where distinct positively stained populations were unavailable.

\section{Cell proliferation assay}

Naive Th cells were stained with CellTrace Violet following the CellTrace Violet Cell Proliferation Kit (Invitrogen) protocol and cultured under activationdifferentiation conditions for Th2 as described previously, in the presence or absence of $15 \mu \mathrm{M} 4 \mu 8 \mathrm{c}$ for 4 days. Flow cytometry was performed using a BD Fortessa and data analysis with FlowJo software.

\section{$N$. brasiliensis infection and splenocyte preparation}

C57BL/6 female mice were subcutaneously injected with $100 \mu \mathrm{l}(300 / 500$ live third stage $N$. brasiliensis larvae per dose). Spleen was taken from infected mice 7 days after infection. Cells were isolated from spleen by smashing the tissue through a 70- $\mu \mathrm{m}$ cell strainer and suspended in RBC lysis buffer (eBioscience). Single-cell suspensions of splenocytes were then stained following FACS staining protocol.

\section{Analysis of bulk RNA-sequencing data}

For each sample, reads were mapped to the Mus musculus genome (GRCm38) using GSNAP with default parameters [33]. Uniquely mapped reads to the genome were counted using htseq-count (http://htseq.readthedocs.io/) and normalized with size factors calculated by DESeq2 [34]. Differentially expressed genes across conditions were identified using DESeq 2 with an adjusted $p$ value cutoff $<0.05$.

\section{XBP1 ChIPmentation}

In vitro differentiated and reactivated Th2 cells were used in ChIP. Two independent biological replicates were performed. Twenty million cells from each sample were crosslinked in $1 \% \mathrm{HCHO}$ (prepared in $1 \mathrm{X}$ DPBS) at room temperature for $10 \mathrm{~min}$, and $\mathrm{HCHO}$ was quenched by the addition of glycine at a final concentration of $0.125 \mathrm{M}$. Cells were pelleted at $4{ }^{\circ} \mathrm{C}$ at $2000 \times g$, washed with ice-cold $1 \mathrm{X}$ DPBS twice, and snapped frozen in liquid nitrogen. The cell pellets were stored in $-80{ }^{\circ} \mathrm{C}$ until the experiments were performed. ChIPmentation was performed according to the version 1.0 of the published protocol [35] with some modifications at the ChIP stage.

Briefly, cell pellets were thawed on ice and lysed in $300 \mu \mathrm{l}$ ChIP Lysis Buffer I (50 mM HEPES.KOH, pH 7.5, $140 \mathrm{mM} \mathrm{NaCl}, 1 \mathrm{mM}$ EDTA, pH 8.0, 10\% Glycerol, 0.5\% NP-40, $0.25 \%$ Triton X-100) on ice for $10 \mathrm{~min}$. Then, cells were pelleted at $4{ }^{\circ} \mathrm{C}$ at $2000 \times g$ for $5 \mathrm{~min}$, washed by $300 \mu \mathrm{l}$ ChIP Lysis Buffer II (10 mM Tris-Cl, pH 8.0, $200 \mathrm{mM} \mathrm{NaCl}, 1 \mathrm{mM}$ EDTA, pH 8.0, $0.5 \mathrm{mM}$ EGTA, $\mathrm{pH}$ 8.0), and pelleted again at $4{ }^{\circ} \mathrm{C}$ at $2000 \times g$ for $5 \mathrm{~min}$. Nuclei were resuspended in $300 \mu \mathrm{l}$ ChIP Lysis Buffer III (10 mM Tris-Cl, $\mathrm{pH} 8.0,100 \mathrm{mM} \mathrm{NaCl}, 1 \mathrm{mM}$ EDTA, $0.5 \mathrm{mM}$ EGTA, $0.1 \%$ sodium deoxycholate, $0.5 \% \mathrm{~N}$-lauroylsarcosine). Chromatin was sonicated using Bioruptor Pico (Diagenode) with $30 \mathrm{~s}$ ON/30 s OFF for 3 cycles. Thirty microliter $10 \%$ Triton X-100 were added into each sonicated chromatin, and insoluble chromatin was pelleted at $16,100 \times g$ at $4{ }^{\circ} \mathrm{C}$ for $10 \mathrm{~min}$. One microliter supernatant was taken as input control. The rest of the supernatant was incubated with $10 \mu \mathrm{l}$ Protein A Dynabeads (Invitrogen) pre-bound with $1 \mu \mathrm{g}$ XBP1 antibody (XBP1 (M-186)X - Santa cruz), in a rotating platform in a cold room overnight. Each immunoprecipitation (IP) was washed with $500 \mu \mathrm{l}$ RIPA Buffer (50 mM HEPES.$\mathrm{KOH}, \mathrm{pH} 7.5,500 \mathrm{mM} \mathrm{LiCl}, 1 \mathrm{mM}$ EDTA, 1\% NP-40, 0.7\% Sodium Deoxycholate, check components) for three times. Then, each IP was washed with $500 \mu \mathrm{l}$ $10 \mathrm{mM}$ Tris, $\mathrm{pH} 8.0$ twice, and resuspended in $30 \mu \mathrm{l}$ 
tagmentation reaction mix $(10 \mathrm{mM}$ Tris.Cl, $\mathrm{pH}$ 8.0, $5 \mathrm{mM} \mathrm{Mg} 2 \mathrm{Cl}, 1 \mu \mathrm{l}$ TDE1 (Nextera)). Then, the tagmentation reaction was put on a thermomixer at $37{ }^{\circ} \mathrm{C}$ for $10 \mathrm{~min}$ at $800 \mathrm{rpm}$ shaking. After the tagmentation reaction, each IP was washed sequentially with $500 \mu \mathrm{l}$ RIPA Buffer twice, and $1 \mathrm{X} \mathrm{TE} \mathrm{NaCl}(10 \mathrm{mM}$ Tris.Cl, $\mathrm{pH}$ 8.0, $1 \mathrm{mM}$ EDTA, $\mathrm{pH} 8.0,50 \mathrm{mM} \mathrm{NaCl}$ ) once. Elution and reverse crosslinking was done by resuspending the beads with $100 \mu$ l ChIP Elution Buffer (50 mM Tris.Cl, pH 8.0, $10 \mathrm{mM}$ EDTA, $\mathrm{pH} 8.0,1 \%$ SDS) on a thermomixer at $65{ }^{\circ} \mathrm{C}$ overnight, $1400 \mathrm{rpm}$. DNA was purified by MinElute PCR Purification Kit (QIAGEN, cat no. 28004) and eluted in $12.5 \mu \mathrm{l}$ Buffer EB (QIAGEN kit, cat no 28004), which yielded $\sim 10 \mu \mathrm{l}$ ChIPed DNA.

The library preparation reactions contained the following:

Ten-microliter purified DNA (from above), $2.5-\mu \mathrm{l}$ PCR Primer Cocktails (Nextera DNA Library Preparation Kit, Illumina Cat no. FC-121-1030), $2.5 \mu \mathrm{l}$ N5xx (Nextera Index Kit, Illumina cat no. FC-121-1012), $2.5 \mu \mathrm{l} \mathrm{N7xx}$ (Nextera Index Kit, Illumina cat no. FC-121-1012), $7.5 \mu \mathrm{l}$ NPM PCR Master Mix (Nextera DNA Library Preparation Kit, Illumina cat no. FC-121-1030). PCR was set up as follows: $72{ }^{\circ} \mathrm{C}, 5 \mathrm{~min} ; 98{ }^{\circ} \mathrm{C}, 2 \mathrm{~min}$; $\left[98^{\circ} \mathrm{C}\right.$, $\left.10 \mathrm{~s}, 63{ }^{\circ} \mathrm{C}, 30 \mathrm{~s}, 72{ }^{\circ} \mathrm{C}, 20 \mathrm{~s}\right] \times 12 ; 10{ }^{\circ} \mathrm{C}$ hold. The amplified libraries were purified by double AmpureXP beads purification: first with $0.5 \mathrm{X}$ bead ratio, keep supernatant, second with 1.4X bead ratio, keep bound DNA. Elution was done in $20 \mu$ l Buffer EB (QIAGEN). One microliter of library was run on an Agilent Bioanalyzer to see the size distribution. Sequencing was done on an Illumina Hiseq2000 platform using the v4 chemistry (75 bp PE).

\section{ChIPmentation analysis}

The reads were first trimmed using Trimmomatic 0.3664 with settings ILLUMINACLIP:NexteraPE-PE.fa:2:30:10 LEADING:3 TRAILING:3 SLIDINGWINDOW:4:15 MIN LEN:30. Peaks were then called using MACS265, merged over time, and annotated using HOMER66.

The quality of the peaks was assessed using the two available replicates of XBP1.

\section{Inferred regulatory cascade of XBP1}

Transcription factors were obtained from the AnimalTFDB 2.0 [36] and were defined as targets of XBP1 if they were intersected by a ChIPmentation peak and differentially expressed between Th2 (control) and $4 \mu 8 \mathrm{c}$-treated Th2. Genes were defined as targeted by these transcription factors if in the STRING version 10 database [37], they had an "expression" mode of interaction with a score greater than 200 with these transcription factors in mouse, and were differentially expressed between Th2 (control) and 4 $48 \mathrm{c}$-treated Th2.

\section{XBP1s overexpression and comparison with drug} treatment

\section{XBP1s cloning}

To generate an pMSCV-XBP1s-IRES-mCherry construct, Flag-XBP1s was amplified from Flag-XBP1spcDNA5/FRT/TO (gift from Prof. David Ron) by PCR (F primer: cgccggaattcagatcttacgtagctagcgCAAATGGACTA CAAAGACGA, R primer: gcggaattgatcccgctcgagcaattgg TTAGACACTAATCAGCTGGG). This Flag-XBP1s fragment was integrated with pMSCV-IRES-mCherry fragment of pMSCV-IRES-mCherry FP (Addgene \#52114, gift from prof. Dario Vignali) cut by bamHI.

\section{Viral transduction}

Virus was produced following the procedure as described in our previous publication (Henriksson et al. 2017, doi: https://doi.org/10.1101/196022). Briefly, platE cells were grown in Advanced DMEM with FBS, pen-strep (PS) and L-glutamine. A mix of 1- $\mu \mathrm{g}$ pCL-Eco (Addgene \#12371, gift from Inder Verma, [38]), 1- $\mu$ g retroviral plasmid, and 2- $\mu$ l PLUS were mixed in $0.5 \mathrm{ml}$ OptiMEM. The mix was vortexed and incubated for $2 \mathrm{~min}$ at room temperature. Six-microliter Lipofectamin LTX was added; the mix pipetted up and down and incubated for $30 \mathrm{~min}$ at room temperature. The mix was added to one well of a six-well plate, containing 80-90\% cells and freshly replaced 1.5-ml OptiMEM. Five hours later, the media was replaced with 2-ml Advanced DMEM. The morning after the media was again replaced with 1.5-ml Advanced DMEM. Forty-eight hours after this replacement, the virus was harvested. The supernatant was filtered by centrifugation $\left(1000 g, 4{ }^{\circ} \mathrm{C}\right.$, $10 \mathrm{~min}$ ) and stored at $4{ }^{\circ} \mathrm{C}$ overnight.

Naive $\mathrm{CD}^{+}{ }^{+} \mathrm{T}$ cells were purified by negative selection using MACS as described above and plated on anti-CD3/CD28-coated plates under Th2 differentiation condition with or without $15 \mu \mathrm{M} 4 \mu 8 \mathrm{c}$ on the same day as the virus harvest. The next day, 40- $\mu$ IMDM + $160-\mu$ l virus supernatant was added into each well of a 96-well plate (round-bottom). To this mix, we added $55 \mu \mathrm{M} \beta \mathrm{ME}$ (2-ME), $8 \mu \mathrm{g} / \mathrm{ml}$ polybrene, and $10 \mathrm{ng} / \mathrm{ml}$ IL4 and IL2. The cells were spun in a centrifuge for $1.5 \mathrm{~h}$ at $1100 \mathrm{~g}$ at $32{ }^{\circ} \mathrm{C}$. The cells were kept for another $3 \mathrm{~h}$ in an incubator at $32{ }^{\circ} \mathrm{C}$. The cells were then kept at $37{ }^{\circ} \mathrm{C}$ overnight. The next morning, the media was replaced with fresh IMDM supplemented with IL4, $\beta M E$, and $15 \mu \mathrm{M} 4 \mu 8 \mathrm{c}$ (or DMSO).

For RNA sequencing: 5 days after $\mathrm{T}$ cell activation, 5000 fluorescent (transduced) cells were FACS-sorted into $20-\mu \mathrm{l}$ RLT buffer and frozen in $-80{ }^{\circ} \mathrm{C}$. The RNA was extracted using $30 \mu \mathrm{l}$ SPRI beads and eluted into 5- $\mu \mathrm{l}$ media of the following composition: $2 \mu \mathrm{dNTP}$ (10 $\mu \mathrm{M}), 2 \mu \mathrm{l}$ Oligo-dT $(100 \mu \mathrm{M})$, and $1 \mu \mathrm{l}$ nuclease-free water. Four microliters of the elute was used as input 
into smart-seq 2 [39]. Pre-amplification was done using 8 PCR cycles. Library preparation was done using Nextera XT at $1 / 4$ of the manufacturer-specified reaction size. The libraries were sequenced on an Illumina HiSeq 2500 50SE. The raw reads are deposited at ArrayExpression (E-MTAB-7104).

Reads were trimmed using Trimmomatic 0.36 using settings -phred33 ILLUMINACLIP:NexteraPE-PE.fa:2:30:10 LEADING:3 TRAILING:3 SLIDINGWINDOW:4:15 MINLEN:30. Reads were mapped using Kallisto 0.44 .0 with settings -b 100 --single -1 180 -s 20 . A custom R script collected the estimated counts into a total count matrix.

Differential expression analysis was performed using DESeq2. The control cells were compared to $4 \mu 8 \mathrm{c}$ treated, with XBP1s overexpression, and with simultaneous $4 \mu 8 \mathrm{c}$ treatment and overexpression. The heatmap shows the fold change of genes that in any comparison has an adjusted $p$ value of $10^{-10}$. Other cut-offs yield similar results.

For cell proliferation assays, naïve cells were stained with CellTrace Violet following the protocol as described above.

For intracellular cytokine IL5 and IL13 detection, XBP1s- or empty vector-transduced cells were sorted by cell sorter (as described above for RNAseq), rested for two more days to propagate, and reactivated in CD3e/ CD28-coated plates for $6 \mathrm{~h}$. The cells were then stained with fixable live-dead dye, fluorescent dye-conjugated anti-IL13 and IL5 antibodies, and analyzed by FACS.

\section{Results and discussion}

In this study, to understand the role of IRE1a-XBP1 pathway, our basic strategy was to use an in vitro Th2 differentiation model (Fig. 1b). Naïve T helper cells were activated by TCR activation in anti-CD3e/CD28-coated plates under Th2 differentiation condition for $72 \mathrm{~h}$, rested for $42 \mathrm{~h}$, and restimulated by TCR activation using anti-CD3e/CD28-coated plates. To perturb IRE1a-XBP1 pathway, we used a well-established drug $4 \mu 8 \mathrm{c}$ that specifically blocks the pathway by inhibiting IRE1a endonuclease activity [40]. The drug was added to the culture media at $15-\mu \mathrm{M}$ concentration at the beginning of the culture and during passage from the activation plate to the resting plate. The choice of drug concentration was determined by its highest IRE1a inhibition efficiency with lowest cell toxicity (Additional file 1: Figure S1). We compared transcriptomes of naive and restimulated Th2 (drug treated and untreated) lymphocytes by RNA sequencing, identified XBP1 transcription factor binding sites in reactivated Th2 by ChIPmentation (ChIP-sequencing), and integrated the genome-wide data to predict direct targets and their regulatory role.

\section{T helper cells switch on the IRE1a-XBP1 pathway during} in vitro activation

Activated and differentiated $\mathrm{T}$ helper cells secrete an abundance of cytokines. Therefore, a well-developed secretory machinery is a prerequisite for cells to adapt to this secretory stress. To predict the involvement of ER-stress/UPR pathway during T helper cell activation, we compared transcriptome of naïve and differentiated Th2 cells (restimulated Th2). Differentially expressed genes as obtained from this comparison were integrated in the "Protein Processing in the Endoplasmic Reticulum" KEGG pathway to visualize the components that are up- or downregulated. The analysis shows that when naïve $\mathrm{T}$ helper cells are activated and differentiated into Th2 cells, they upregulate expression of genes involved in the ER stress pathway (Additional file 1: Figure S2). Several factors that have previously been characterized as controllers of protein folding and secretion, including XBP1 itself, are upregulated during $\mathrm{T}$ helper cell differentiation.

To validate this prediction, and specifically investigate the involvement of the IRE1a-XBP1 pathway, we measured IRE1a mRNA and protein expression in Th2 lymphocytes differentiated and reactivated in vitro (Fig. 1b). The cells were analyzed by qPCR and Western blot to compare the mRNA and protein respectively. We found that both mRNA and protein level were upregulated in activated $\mathrm{T}$ helper cells (Fig. 1c, left and middle panel). It is known that phosphorylation of IRE1a denotes its functional state. We observed that the protein is phosphorylated in activated Th2 lymphocytes (Fig. 1c, right panel). This increased phospho-IRE1a can be explained by the increased synthesis of the protein, though we cannot exclude the possibility of increased kinase activity and auto-phosphorylation. The densitometric analysis of Western blot band suggests that both mechanisms, upregulation of protein synthesis and increased phosphorylation, are involved. Protein upregulation increased threefold, but the phospho-protein increased 4.5-fold (Fig. 1c).

Activated IRE1a splices the unspliced XBP1 (XBP1u) mRNA and produces a spliced XBP1 (XBP1s) mRNA isoform. We observed increases in the spliced form of XBP1 (XBP1s), both at mRNA and protein levels, upon $\mathrm{T}$ helper cell activation (Fig. 1d, e). Tunicamycin was used as a positive control. It is a drug that inhibits $N$-linked glycosylation and thereby causes accumulation of unfolded proteins (i.e., endoplasmic reticulum (ER) stress), and increases XBP1s by enhancing IRE1a activity. Specific inhibition of the IRE1a endonuclease activity by treating the cells with $4 \mu 8 \mathrm{c}$ [40] abolished both the XBP1s mRNA and protein isoforms, confirming that the formation of the spliced form was dependent on IRE1a activity (Fig. 1d, e). 
These results confirm that the IRE1a-XBP1 pathway is conserved in Th2 lymphocytes and upregulated during in vitro $\mathrm{T}$ helper cell activation. Next, we set out to investigate whether this also holds in vivo.

\section{In vivo activated T helper cells upregulate the IRE1a-XBP1 pathway}

To test whether the IRE1a-XBP1 pathway is operational in $\mathrm{CD}_{4}^{+} \mathrm{T}$ cells in vivo, we infected C57BL/6 mice with the helminth parasite Nippostrongylus brasiliensis, a well-established model of Th2-driven immune responses [32, 41, 42]. After 7 days post-infection, we analyzed $\mathrm{XBP} 1 \mathrm{~s}$ protein expression in $\mathrm{T}$ helper cells by flow cytometry. We found $\mathrm{T}$ helper cells from worm-infected mice express significantly more XBP1s compared to uninfected control mice, suggesting an upregulation of the pathway (Fig. 2).

These results confirm that the pathway is active in vivo. Therefore, we set out to dissect the pathway using genome-wide approaches in Th2 lymphocytes.

\section{Genome-wide transcriptomic analysis of differential gene expression reveals IRE1a-XBP1-regulated genes}

To capture a global gene regulatory role of the IRE1aXBP1 pathway, we compared in vitro activated Th2 cells to cells with inhibited IRE1a endonuclease activity by adding $4 \mu 8 \mathrm{c}$ into the cell culture media. We then compared the transcriptomes of activated Th2 lymphocytes with or without inhibition of the IRE1a-XBP1 pathway. Transcriptomes of $4 \mu 8 \mathrm{c}$-treated and untreated Th2 cells were obtained by mRNA sequencing (RNA-seq). Quality control of the RNA sequencing data is shown in Additional file 1: Figure S3. Comparing transcriptomes of naïve and activated Th2 lymphocytes, we found that 10995 genes were differentially regulated upon Th2 activation. Inhibition of the IRE1a-XBP1 pathway by $4 \mu 8 \mathrm{c}$ treatment resulted in differential expression of 3144 genes as compared to the untreated Th2 control (Fig. 3a, Additional file 1: Figure S3 right panel). Two thousand six hundred seventy of these genes were involved in Th2 differentiation (Fig. 3a). Hierarchical clustering of the genes reveals the groups of genes up- and downregulated upon $4 \mu 8 \mathrm{c}$ treatment (Additional file 1: Figure S3, right). Detailed examination of these genes revealed many to be associated with the unfolded protein response and ER-stress, indicating a major impact of the IRE1a-XBP1 pathway (Fig. 3b) on these biological processes. The complete list of differentially expressed genes can be found in Additional file 2: Table S1. Gene Ontology (GO) analysis of these differentially expressed genes upon $4 \mu 8 \mathrm{c}$ treatment to Th2 cells (i.e., IRE1a-XBP1 pathway regulated genes) showed that they are enriched in the following biological processes: "Response to ER stress" (GO:0006950), "Regulation of signal transduction" (GO: 0009966), "Cytokine production" (GO:0001816), "cell proliferation" (GO:0008283), "cell cycle" (GO:0007049), and Immune response (GO:0006955) (Fig. 3c). These changes in the gene expression patterns upon IRE1a inhibition suggest extensive involvement of XBP1 transcription factor in Th2 activation and proliferation, as well as

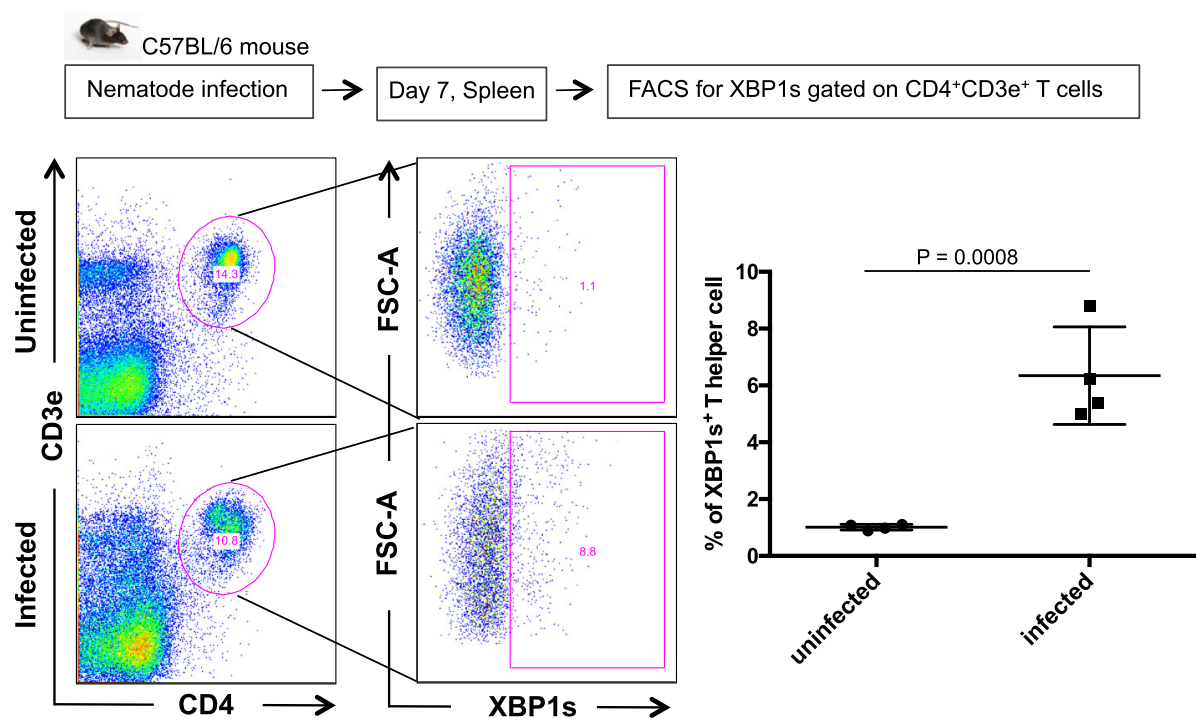

Fig. 2 T helper cells upregulate IRE1a-XBP1 pathway in vivo during infection. Splenocytes from nematode (Nippostrongy/us brasiliensis)-infected mouse (7 days post-infection) were stained with a PE-conjugated anti-XBP1s antibody and analyzed by flow cytometry (gating strategy: singlet > live cells $>\mathrm{CD}^{+} \mathrm{CD}^{+} \mathrm{e}^{+}>\mathrm{XBP} 1 \mathrm{~s}^{+}$). One representative FACS profile is displayed (left panel), and the graph containing all results $(n=4)$ is shown in the "right panel" 
a

Naïve $\rightarrow$ Th2

$\mathrm{Th} 2 \rightarrow \mathrm{Th} 2+4 \mu 8 \mathrm{c}$

8325

$2670 \quad 474$

b
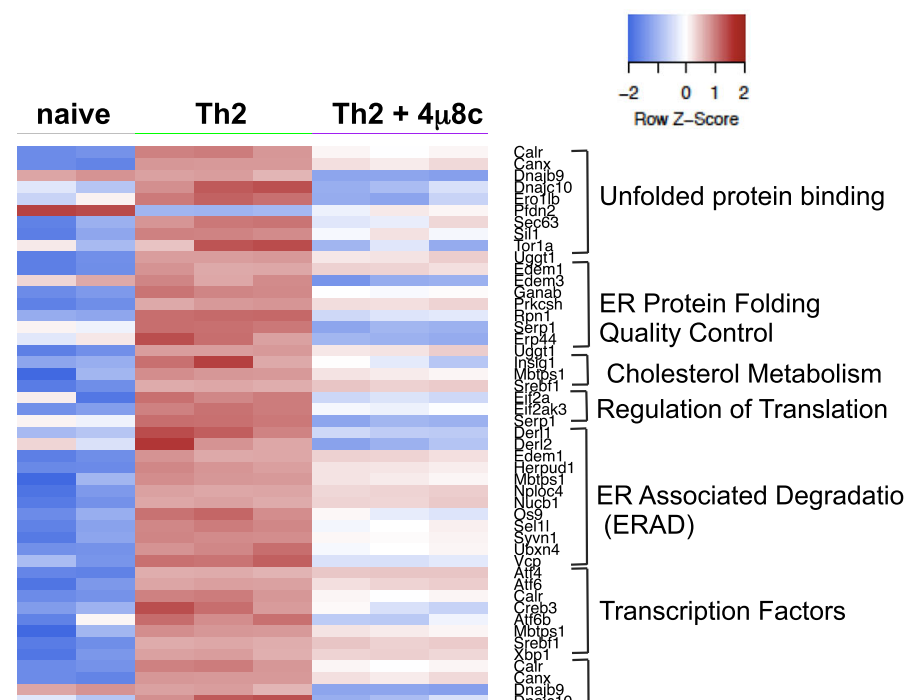

Cholesterol Metabolism

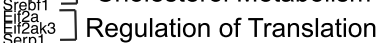

$\mathrm{Ber}_{\text {Berp }}{ }^{2}$

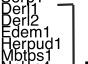

ER Associated Degradation (ERAD)

Transcription Factors

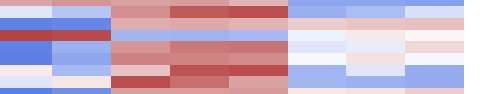

Protein Folding

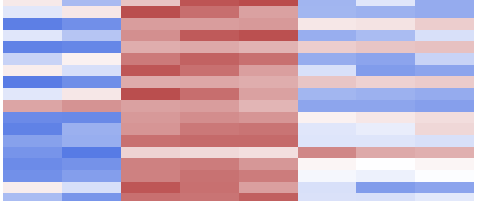

Protein Disulfide

Isomerization

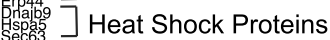

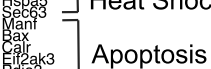

C

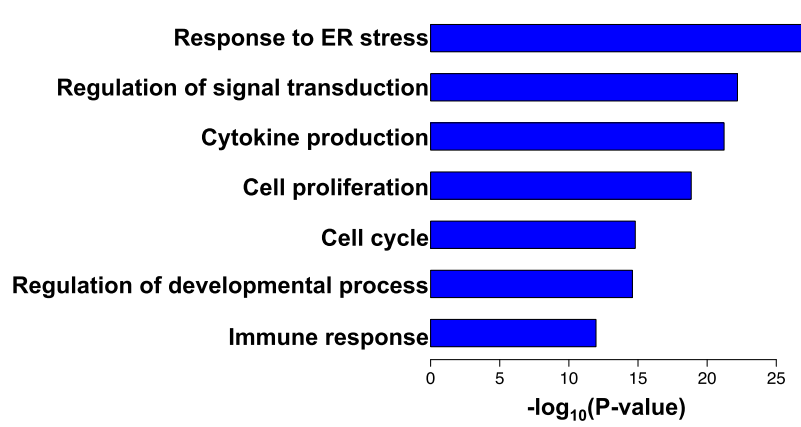

Fig. 3 (See legend on next page.) 
(See figure on previous page.)

Fig. 3 Differential gene expression in Th2 due to the inhibition of IRE1a-XBP1 by $4 \mu 8 c$. Naive T helper cells were activated under Th2 differentiation conditions in the presence or absence of $4 \mu 8 \mathrm{c}$. Cells were activated in anti-CD3e and anti-CD28 antibody-coated plates for 3 days, rested for 2 days, and reactivated in coated plates for $6 \mathrm{~h}$. The RNAseq data were analyzed for differential gene expression. a Venn diagram showing the numbers of differentially expressed genes in different experimental conditions. "Naïve $\rightarrow$ Th2" indicates the differentially expressed genes between naïve T helpers

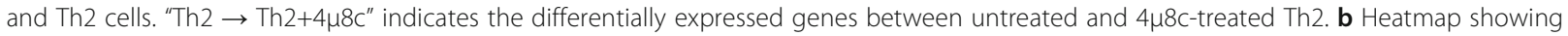
differentially expressed genes that are well known to be involved in resolution of ER stress imposed by unfolded protein response. The heatmap shows scaled expression values denoted as row Z-score, in red-blue color scale with red indicating increased expression and blue indicating decreased expression. c Gene ontology (GO) analysis of the differentially expressed genes between Th2 and 4 $48 \mathrm{c}$-treated Th2

differentiation. Therefore, we set out to find the genome-wide chromatin occupancy patterns of the XBP1 transcription factor.

\section{XBP1 ChIPmentation reveals XBP1 direct target genes in Th2 cells}

To identify the genome-wide chromatin occupancy of XBP1, we performed ChIPmentation, a recently developed method that has been shown to be faster, more sensitive, and robust than traditional ChIP-seq approaches [35], using a ChIP-grade antibody against $\mathrm{XBP} 1$. In vitro differentiated and reactivated Th2 cells were used for the XBP1 ChIP. Two independent biological replicates were performed. We obtained 19.3 million and 22.4 million pair-end reads for each replicate respectively. Using MACS2 [43] with a $q$ value less than 0.01 and fold enrichment over 5, we identified 9031 and 7662 peaks, respectively, in the two replicates. Overlapping analysis using bedtools [44] suggested 5892 peaks were present in both replicates. Therefore, we only focused on these 5892 peaks for the downstream analysis.

As expected, binding peaks were identified around promoter regions in known XBP1 target genes, such as Hspa5 that encodes ER-chaperone protein $\mathrm{BiP}$ also known as Grp78; a binding event was also observed around the promoter of XBP1 itself (Fig. 4a), indicating potential auto-regulation of XBP1. To find out the genomic features associated with the XBP1 binding sites, we compared its peak location to the RefSeq genes using HOMER [40]. The majority of the XBP1 binding peaks were located within promoter (defined as upstream $1000 \mathrm{bp}$ and downstream $500 \mathrm{bp}$ relative to annotated transcriptional start sites) (36\%) and intronic (35\%) regions, and distal intergenic binding event (25\%) were also frequently observed (Fig. 4b). The genomic distribution of XBP1 peaks indicates that it binds both promoters and potential enhancers.

To further characterize the XBP1 regulome, we performed de novo motif discovery using HOMER [45] to identify enriched DNA motifs within XBP1 binding regions. The top motif identified is the consensus sequence GCCACGT, which is almost identical to the human XBP1 binding motif defined in breast cancer cell lines (Fig. 4c) [46]. This indicates highly conserved binding specificities of XBP1 between human and mouse and across cell types. The top motif enriched in our mouse data also resembles the XBP1 motif from the JASPAR database [47], again supporting the high quality of our ChIPmentation data. The second most enriched motif is the NF-Y binding motif (Additional file 1: Figure S4C). Interestingly, the NF-Y motif has been frequently found around promoter regions of cell cycle genes, especially genes involved in G2/M cell cycle regulation $[48,49]$. Both the XBP1 motif and the NF-Y motif co-occur around a subset of 258 XBP1 binding peaks (Fig. 4d), indicating potential cooperation between XBP1 and NF-Y transcription factors to regulate a subset of target genes. The list of target genes that are potentially co-regulated by XBP1 and NF-Y is displayed in Additional file 3: Table S2, and a complete list of XBP1 targets is also provided in Additional file 3: Table $\mathrm{S} 2$. The top five enriched motifs are displayed in Additional file 1: Figure S4C. To investigate the functions of XBP1-bound genes, we used GREAT [50] to characterize XBP1 binding peaks. Most of the significant GO terms are related to protein folding and ER-stress (Fig. 4e), which is consistent with the known biological role of XBP1.

Altogether, the ChIPmentation experiments predict a role of XBP1 in enhancing protein folding and secretion, as well as activation of Th2 lymphocytes.

\section{Integration of transcriptomic data and ChIP-seq data to unravel the XBP1-controlled gene regulatory network}

To reveal the XBP1-regulated direct target genes and its transcriptional regulatory network, we integrated the genome-wide transcriptomic data and ChIPmentation data. A direct target gene is defined by its differential expression upon IRE1a inhibition (i.e., $4 \mu 8 \mathrm{c}$ treatment) and XBP1 transcription factor occupancy at the gene locus. We found 1143 direct target genes in Th2, of which 122 targets were previously reported as XBP1 direct target in other cell types (i.e., muscle, pancreatic $\beta$-cell, and plasma cell) (Fig. 5a). In this context, 1021 genes can be considered as Th2-specific. XBP1 action over its direct targets has no defined direction, containing genes upand downregulated. The top 38 genes following either of these patterns are shown in Fig. $5 \mathrm{~b}$, and the complete list can be found in Additional file 4: Table S3. The most 
a

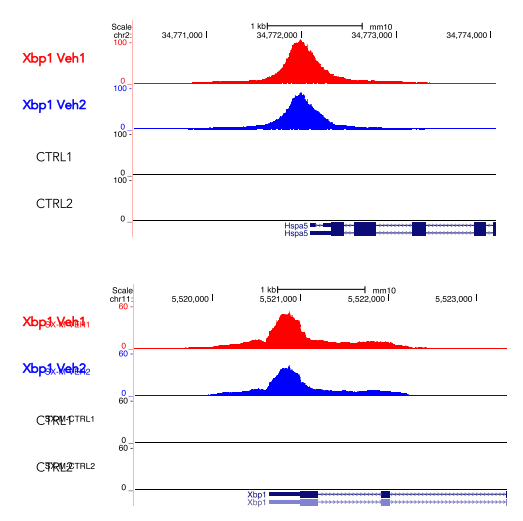

C

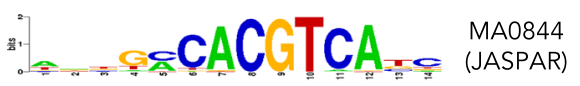

$$
\begin{aligned}
& \text { CCCACGTO } \begin{array}{c}
\text { Human XBP1 } \\
\text { (Chen et al. 2014) }
\end{array} \\
& \text { CACGTE } \quad \begin{array}{c}
\text { Mouse XBP1 } \\
\text { (this study) }
\end{array}
\end{aligned}
$$

b
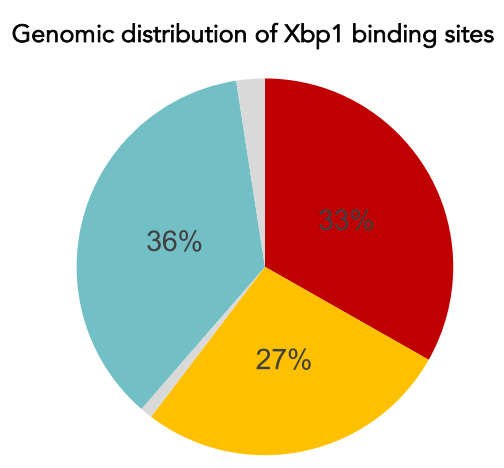

- Promoter-TSS Intergenic

Exon

antron

d

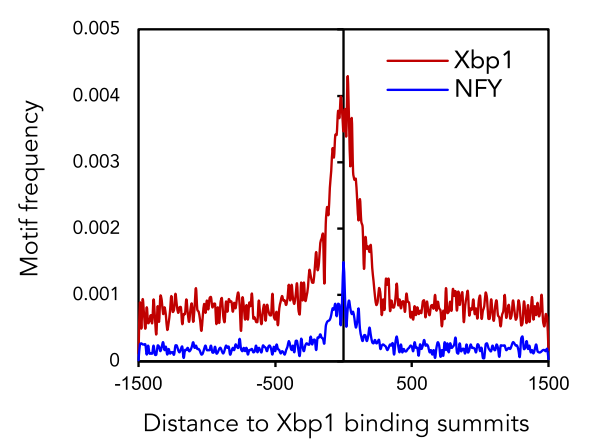

e

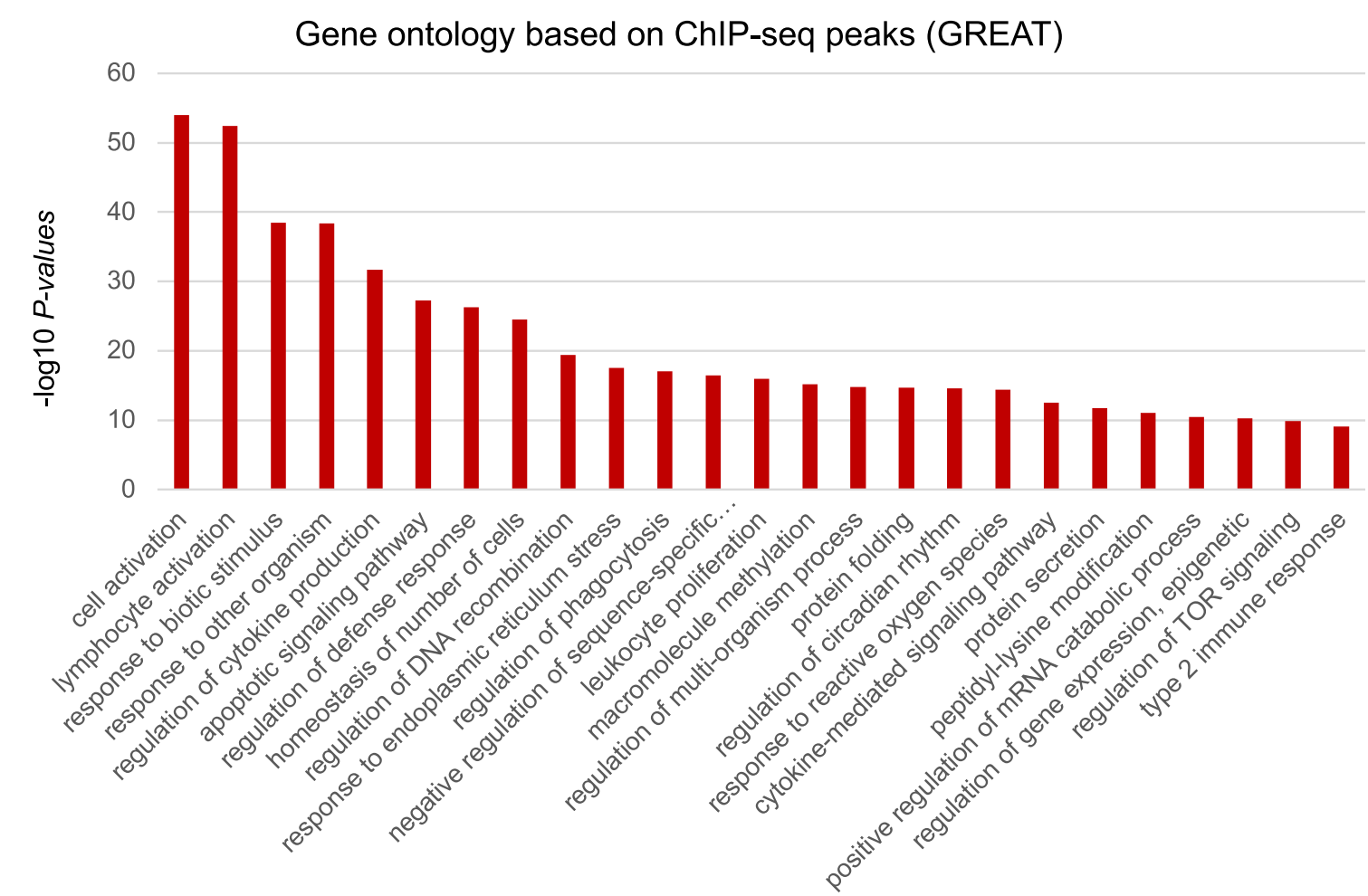

Fig. 4 (See legend on next page.) 
(See figure on previous page.)

Fig. 4 Genome-wide chromatin occupancy of XBP1 transcription factor in Th2 lymphocyte. XBP1 ChIPmentation was performed in in vitro differentiated Th2 cells to obtain genome-wide XBP1 chromatin occupancy. a Snapshot of XBP1 binding peaks around indicated representative genes from the UCSC genome browser. $\mathbf{b}$ Genomic distribution of XBP1 binding peaks. The sector corresponding to the promoter includes sequences up to $1 \mathrm{~kb}$ upstream and $100 \mathrm{bp}$ downstream from the TSS. c Comparing the XBP1 motifs from the JASPAR database (top), ChIP-seq of the human breast cancer cell lines (middle), and mouse Th2 lymphocytes (bottom). $\mathbf{d}$ Motif frequencies of XPB1 and NF-Y around the binding peaks of XBP1. e Biological processes' $\mathrm{GO}$ terms enriched within XBP1 binding peaks analyzed by GREAT

significant identified biological process and pathways are related to protein folding and ER-stress (Additional file 1: Figure S5), which are consistent with its known biological roles, and also include novel Th2-specific targets.

Despite the preponderance of XBP1's role in controlling this pathway, other transcription factors are also found to be involved. To examine the regulatory cascade that follows XBP1 regulation, we built a transcriptional regulatory network by extracting annotated transcription factors with promoter or exonic/intronic ChIP-seq peaks (Fig. 5c). The complete list of the transcription factors can be found in the Additional file 5: Table S4. This network was further complemented by adding differentially expressed genes that have annotated interactions with the target transcription factors in the STRING database [37] (Additional file 6: Table S5).

The transcription factors that are directly regulated by XBP1 can be categorized into three broad functional categories involved in the following: resolution of protein secretory ER stress, regulation of cell cycle and proliferation, and controlling effector immune cell function. The ER-stress involved transcription factors are likely to facilitate cytokine secretion in Th2 lymphocyte. This prediction is based on the previous reports from secretory cells such as pancreatic acinar cells and plasma cells. These transcription factors, namely Bhlha15, Atf3, Atf6, Atf6b, Atf4, and Creb312, have been shown to be involved in secretory stress adaptation of the ER $[9,15,51,52]$.

The purpose of cell proliferation and cell cycle-related transcription factors could be to facilitate the controlled rapid expansion of activated Th2 cells. The immune response-related factors are likely involved in Th2 differentiation and cytokine production. Therefore, we wanted to test the effect of XBP1s downregulation in cytokine secretion, cell proliferation, and cytokine production.

\section{The IRE1a-XBP1 pathway controls cytokine secretion in T helper cells}

The genome-wide comparison of XBP1s-regulated genes predicts that the factor is involved in secretion of cytokines. To validate this prediction, we blocked IRE1a endonuclease activity in Th2 cells and analyzed the cell culture supernatant to quantify the IL4 level by ELISA. We selected IL4 as a testable candidate cytokine because its mRNA and protein are unchanged by downregulation of XBP1 (Additional file 1: Figure S6A left panel, Fig. 6 left and middle panel of top row). We found that the secretion of IL4 is significantly inhibited in $4 \mu 8 \mathrm{c}$-treated cells (Fig. 6, right panel of top row). As expected, this result supports the involvement of the IRE1a-XBP1 pathway in facilitating cytokine secretion in Th2 cells as predicted. The inhibition of the pathway during restimulation phase has no significant inhibitory effect on IL4 secretion (Additional file 1: Figure S6B). This result suggests that the XBP1s is required during Th2 differentiation, possibly for the development of an efficient secretory machinery.

\section{The IRE1a-XBP1 pathway controls IL13 and IL5 cytokine expression}

IL5 and IL13 are two prominent type 2 cytokines that are involved in eosinophilia, allergies and helminth infection. We found that inhibition of IRE1a-XBP1 pathway significantly suppresses the IL5 and IL13 protein expression and secretion into the culture medium (Fig. 6 right panels of middle and bottom row). Bioinformatics analysis of the Th2 transcriptome predicts that the IRE1a-XBP1 pathway positively controls IL5 and IL13 gene expression, because both the genes were identified as differentially expressed genes upon IRE1a inhibition (Additional file 2: Table S1). We validated this prediction by RT-qPCR-mediated gene expression analysis (Additional file 1: Figure S6A, middle and right panel) and flow cytometry (Fig. 6). These results suggest a transcriptional involvement of the pathway regulating IL5 and IL13. Notably, the IL4 mRNA and protein levels are not affected indicating specific regulation of IL5 and IL13.

\section{IRE1a-XBP1 pathway facilitates activation-dependent T helper cell proliferation}

Cell proliferation rate is a resultant outcome of positive and negative regulators' interaction. We observed that genes encoding both positive and negative regulators of cell proliferation genes are differentially expressed when the IRE1a-XBP1 pathway was blocked by $4 \mu 8 \mathrm{c}$ (Fig. 7a, left panel, Additional file 7: Table S6), of which many genes were found to be direct targets of XBP1 (Fig. 7a, right panel, Additional file 8: Table S7). This observation predicts a change in proliferation rate upon IRE1a inhibition. Therefore, we were interested in checking the 


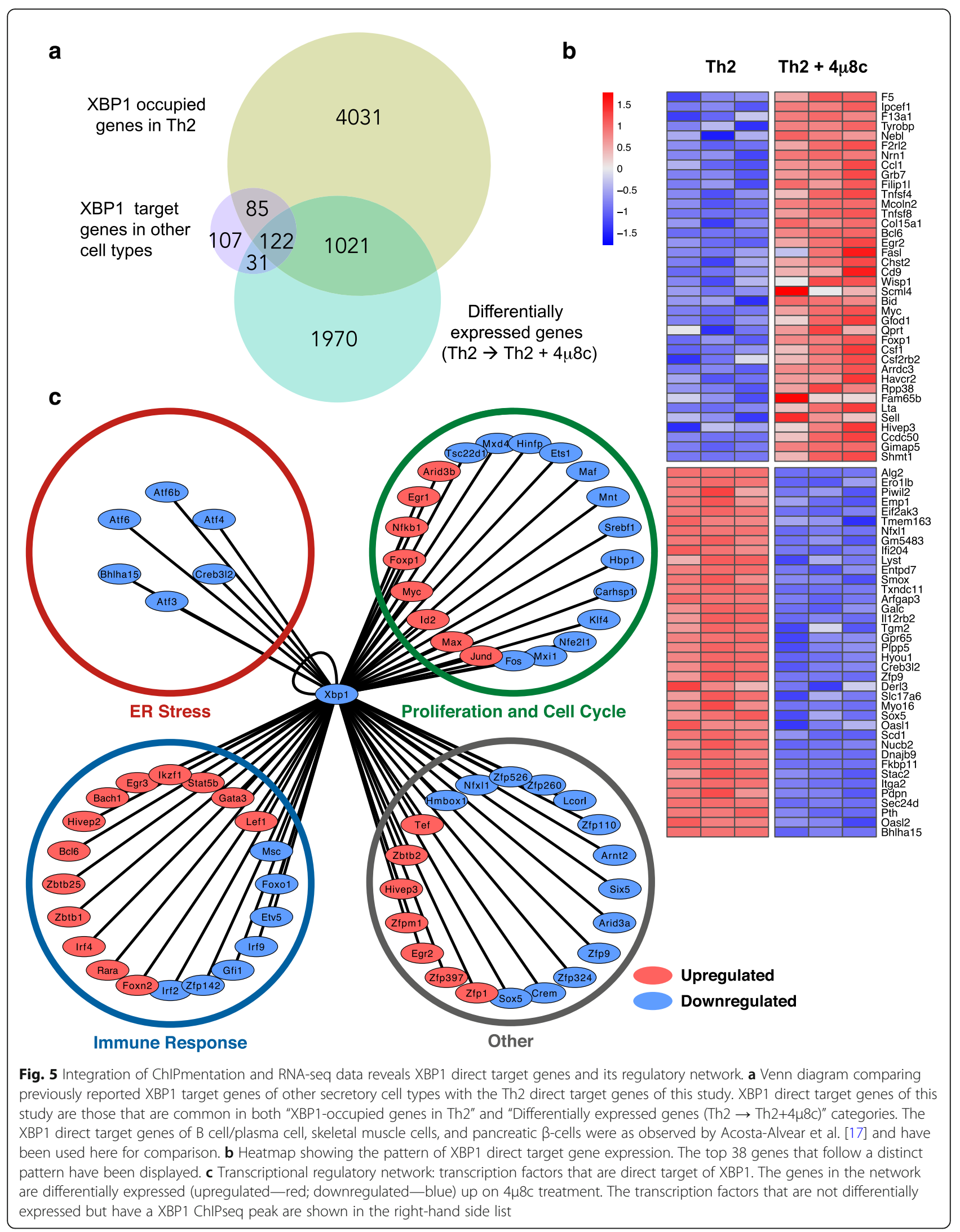




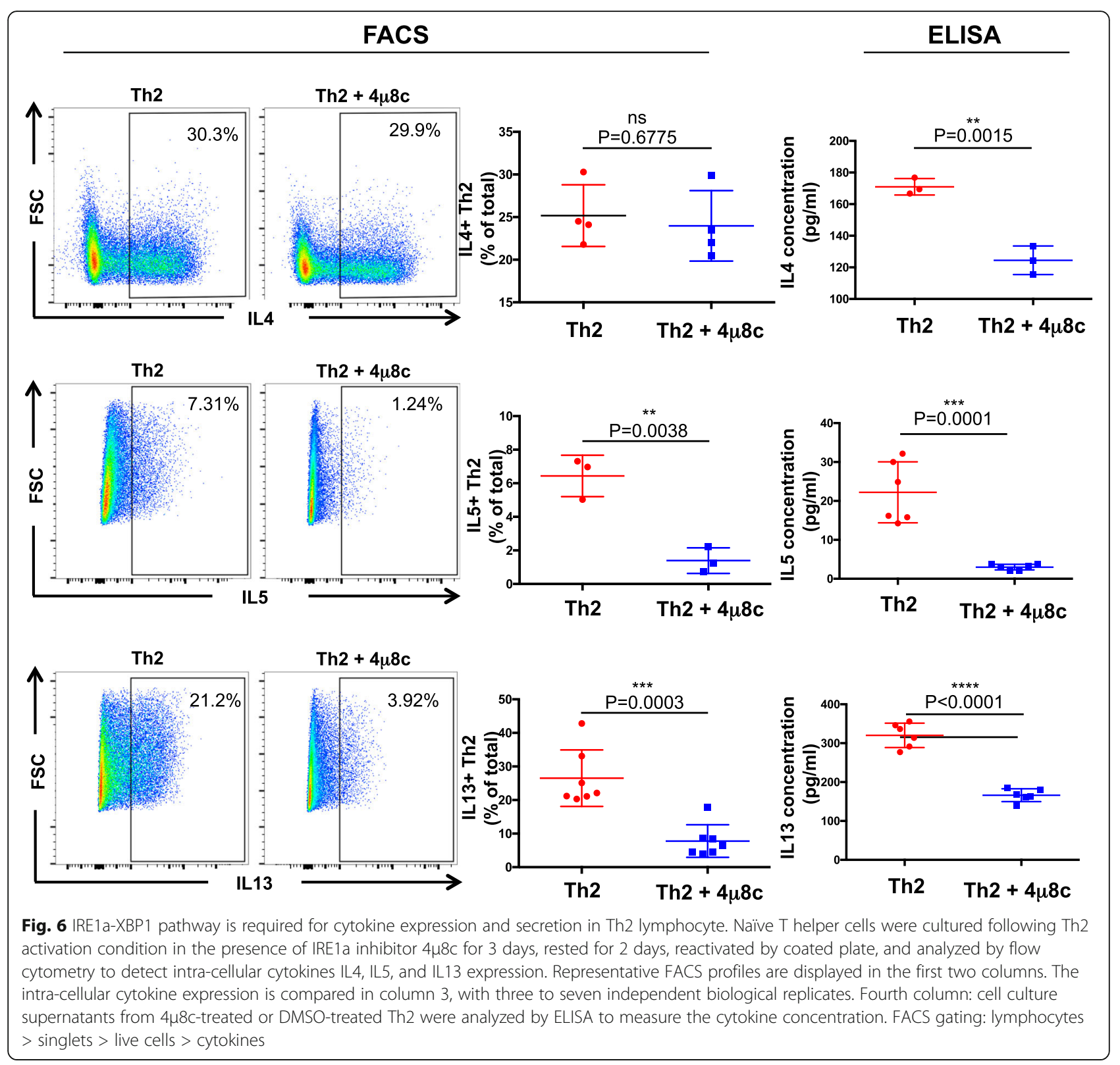

effect of IRE1a-XBP1 inhibition on cell proliferation. We performed cell proliferation assay using Th2 cells. Naïve splenic $\mathrm{CD} 4^{+} \mathrm{T}$ cell were labeled with CellTrace violet and activated under Th2 differentiation condition in the presence or absence of $4 \mu 8 \mathrm{c}$. The fluorescent dye decay was monitored by flow cytometry. We found that downregulation of XBP1s inhibits cell proliferation significantly (Fig. 7b), but does not induce cell death (Additional file 1: Figure S7).

$\mathrm{T}$ helper cell proliferation is associated with differentiation and cytokine production. The reduced IL5 and IL13 expression (Fig. 6) could potentially be explained by the fact that cell proliferation is retarded. However, if reduced proliferation was the primary reason for lack of secretion, IL4 production would also be inhibited. Yet, we observed no significant change in IL4 expression upon IRE1a inhibition (Fig. 6, Additional file 1: Figure S6A). To examine this discrepancy further, we performed cell proliferation assays using IL13-GFP and IL4-GFP reporter mouse lines. In IL4-GFP expressing Th2 cells, we observed an inhibition of IL4 production in the first few generations of cell division up to $72 \mathrm{~h}$ upon $4 \mu 8 \mathrm{c}$ treatment (Additional file 1: Figure S8). But at $96 \mathrm{~h}$, the difference in IL4 expression becomes insignificant regardless of which generation of cell division the cells are in. This observation suggests that the retardation of proliferation due to the IRE1a inhibition is not sufficient to inhibit IL4 expression. In contrast, in 
a
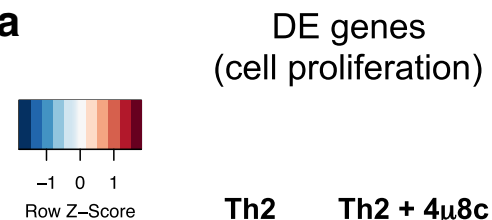

cell proliferation)

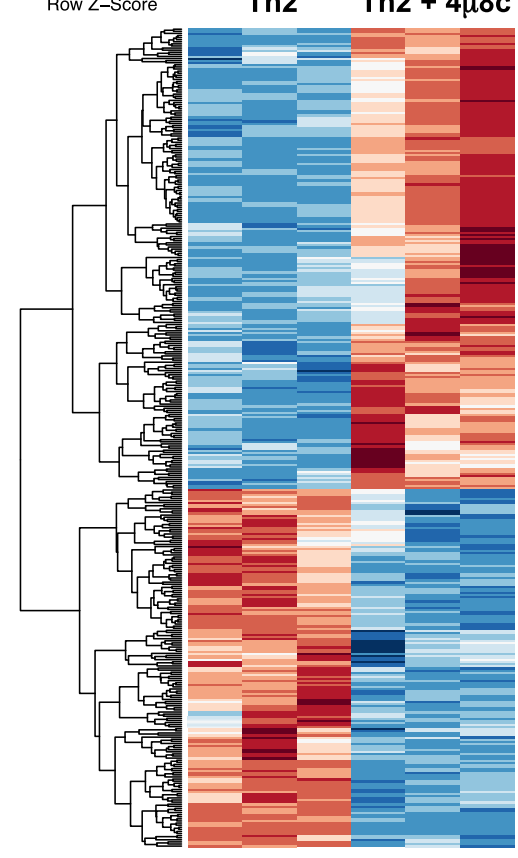

b

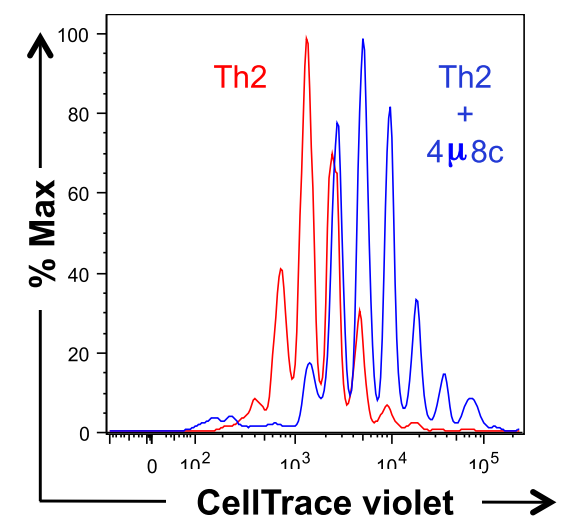

\section{XBP1 target genes} (cell proliferation )

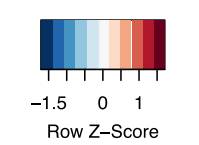

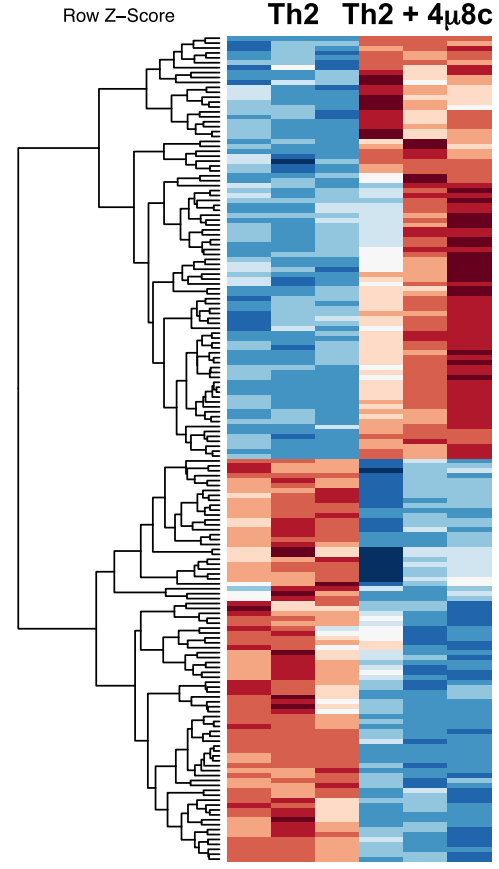

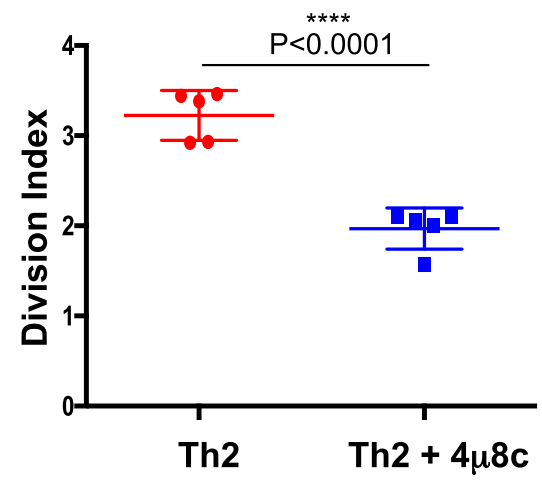

Fig. 7 IRE1a-XBP1 pathway promotes activation-dependent Th2 cell proliferation and cell cycling. a Left panel: hierarchical clustering of differentially expressed cell proliferation-associated genes in the $4 \mu 8 \mathrm{c}$-treated and untreated Th2 transcriptome. Right panel: hierarchical clustering of XBP1 direct target genes that are known to be involved in cell proliferation. The heatmap shows scaled expression values denoted as row Z-score, in red-blue color scale with red indicating increased expression and blue indicating decreased expression. $\mathbf{b}$ Splenic naïve $T$ helper cells were stained with CellTrace Violet dye and activated for $72 \mathrm{~h}$ under Th2 differentiation conditions and

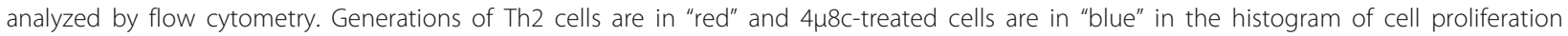
(left panel, one representative experiment). Graphical representation of division index as obtained from five independent biological replicates (right panel) 
IL13-GFP, we observed the decrease in IL13 expression from the very first generation and this continues throughout the later generations (Additional file 1: Figure S9).

\section{IRE1a inhibition delays cell cycle progression through the $S$ and $\mathrm{G} 2 / \mathrm{M}$ phase}

Bioinformatics analysis of differentially expressed genes (Th2 vs $4 \mu 8 \mathrm{c}$-treated Th2) and XBP1 direct target genes reveals several genes that are involved in controlling cell cycle progression through different stages (i.e., G1, S, $\mathrm{G} 2 / \mathrm{M}$ ) were clustered into two groups up- or downregulated (Fig. 8a). We took genes differentially expressed in $4 \mu 8 \mathrm{c}$-treated Th2 compared to untreated Th2 (adjusted $p$ value $<0.05$ ) (Fig. 8a, left, Additional file 9: Table S8) and the genes differentially expressed XBP1 direct target genes (Fig. 8a, right, Additional file 10: Table S9), and checked for known roles across distinct cell cycle stages using either a manually curated list based on RNA-seq data or published database [53]. We found many genes from all cell cycle stages (i.e., G1, S, and G2/M) were affected. To identify the cell cycle stages regulated by IRE1a-XBP1 pathway, we created and used a transgenic FUCCI (fluorescent ubiquitin cell cycle indicator) mouse strain that expresses mCherry-tagged Cdt1 and mVenus-tagged Geminin protein. The strain is similar to the one used in [31]. The G1 cells are mCherry+ mVenus- (Q3; Fig. 8b), G1-S cells are mCherry+ mVenus+ (Q2; Fig. 8b), and SG2M are mCherry- mVenus+ (Q1; Fig. 8b), while cells in mitosis and entering G1 are mCherry- mVenus- (Q4; Fig. 8b). We compared cell cycle profiles of vehicle and $4 \mu 8 \mathrm{c}$-treated Th2 cells during $\mathrm{T}$ cell activation. We found that cells accumulated in the $\mathrm{S}$ and/or G2/M phase when the IRE1a-XBP1 pathway is blocked (Fig. 8b). Similar results were obtained in a different approach using BrdU incorporation assay with DAPI staining (Additional file 1: Figure S10).

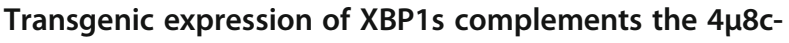 mediated inhibition of IRE 1 a endonuclease activity}

To test whether the observed $4 \mu 8 \mathrm{c}$-treated phenotypes were due to the loss of XBP1s, we performed complementation assays by transducing a XBP1s expression vector into the Th2 cells in vitro. The vector encoded the spliced form of XBP1 (XBP1s), whose function is independent of IRE1a function. We found that stable ectopic expression of XBP1s negates the effect of $4 \mu 8 \mathrm{c}$ treatment and there is no significant change in the transcriptome upon $4 \mu 8 \mathrm{c}$ treatment when Th2 cells overexpress XBP1s (Additional file 1: Figure S11A). XBP1s overexpressing Th2 cells proliferate and differentiate normally in presence of $4 \mu 8 \mathrm{c}$ (Additional file 1: Figure S11B and S11C respectively). These results strongly suggest that the phenotypes observed upon $4 \mu 8 \mathrm{c}$ treatment are due to the loss of XBP1s.

\section{Conclusions}

The primary aim of this study was to investigate the role of XBP1 transcription factor in Th2 lymphocytes and to identify the Th2-specific XBP1 target genes and their involvement regulating Th2 cell biology. We showed evidence that the IRE1a-XBP1 pathway is engaged in resolving secretory stress to meet robust cytokine synthesis and secretion, and controls multiple important cellular properties of $\mathrm{T}$ helper lymphocyte. It regulates activation-dependent $\mathrm{T}$ helper cell proliferation and cytokine production, the two key features of $\mathrm{T}$ helper cell during activation. The study revealed a large transcriptional regulatory network governed by XBP1. The comprehensive repertoire of XBP1-regulated genes and its genome-wide binding map provides a valuable resource for future work. We built a transcriptional regulatory map by integrating XBP1 ChIPmentation and RNAseq data, which portrays the bigger picture of the involvement of the XBP1 transcription factor in regulating target genes including other transcription factors. To visualize the data, we created an easily browsable online database available at http://data.teichlab.org.

ER-stress is known to be involved in several pathological situations. The pathway promotes cancer progression by providing metabolic advantage to the neoplastic cancer cells to acclimatize to the stressed tumor microenvironment. During the anti-tumor immune response, the XBP1 pathway induces tolerance in DCs. The pathway promotes asthmatic, allergic, and eosinophilic immune reactions and is involved in immunometabolism of macrophages in obesity. The pathway can be modulated by drug such as $4 \mu 8 \mathrm{c}$ and STF-083010 and is under intensive investigation. Further studies will have to be carried out to determine whether the modulation of the pathway can bring patients' benefit. This study shows evidence that perturbation of the IRE1a-XBP1 pathway may interfere with normal physiological activation of Th2 and could be exploited in settings where Th2 lymphocytes are pathologic such as asthma, allergies, and eosinophilia. Two prominent cytokines, IL5 and IL13, which promote allergies and eosinophilia, are under the control of IRE1a-XBP1 pathway in Th2 lymphocytes. In future, locus-specific mechanistic dissection of the XBP1-mediated transcription process in Th2 lymphocytes and in vivo immunobiological studies on novel Th2-specific XBP1 target genes are required to understand how the XBP1 transcription factor orchestrates locus control and to what extent it controls Th2-mediated immune responses. 
DE genes (cell cycle)

\section{a}

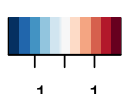

Row Z-Score

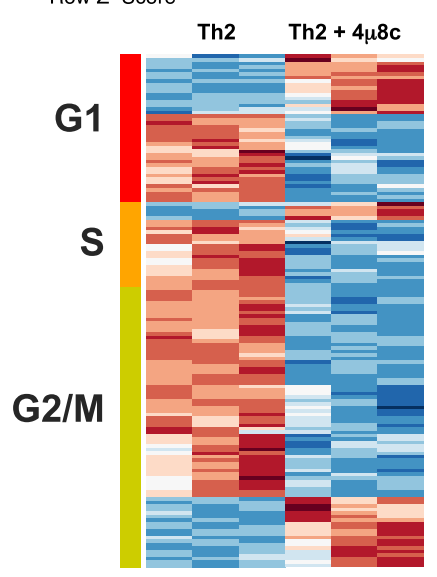

b

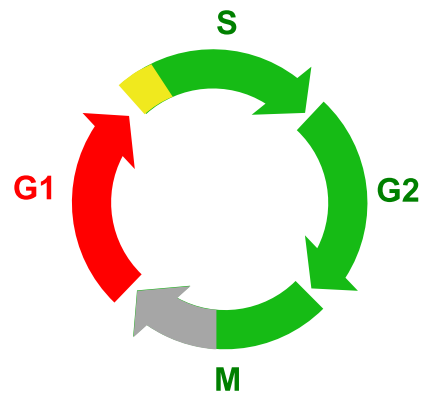

XBP1 target genes (cell cycle)
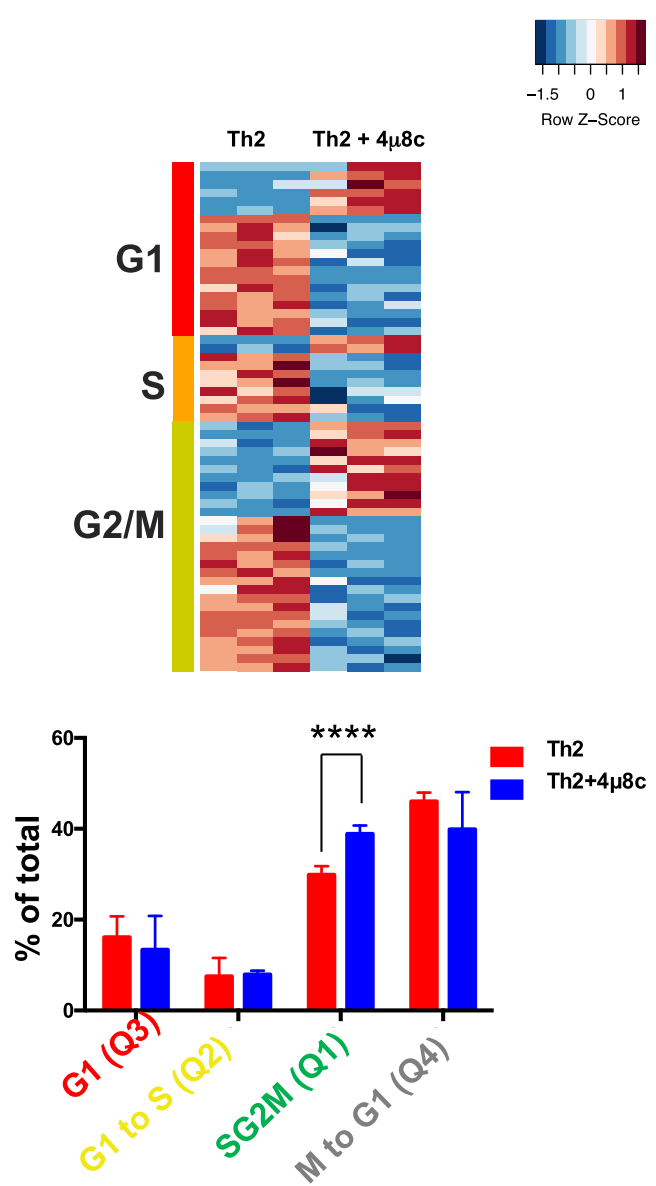

$\mathrm{Th} 2+4 \mu 8 \mathrm{c}$

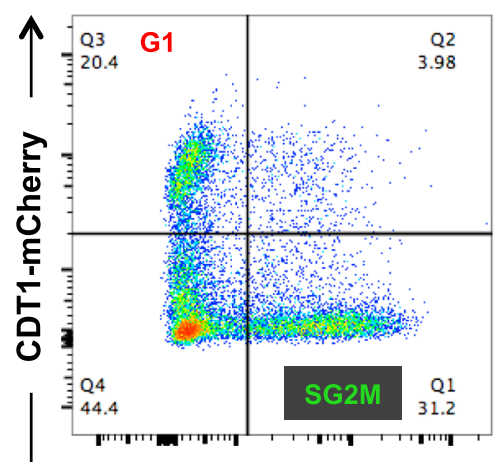

\section{Geminin-Venus}

Fig. 8 IRE1a inhibition delays cell cycle progression through the S and G2/M phase. a Left panel: heatmap of differentially expressed cell cycle stage-associated genes in the $4 \mu 8 \mathrm{c}$-treated and untreated Th2 transcriptome. Right panel: heatmap of XBP1 direct target genes that are known to be involved in cell cycling. The heatmap shows scaled expression values denoted as row Z-score, in red-blue color scale with red indicating increased expression and blue indicating decreased expression. b Cell cycle analysis of Th2 lymphocytes after $72 \mathrm{~h}$ of activation, using FUCCl mouse line that express mCherry-tagged CDT1 and Venus-tagged GEMININ. Upper left: diagrammatic representation of cell cycle stages in used FUCCI mouse. Upper right: comparison of cells (\% of total) obtained from different stages of cell cycle in Th2 and $4 \mu 8 c$-treated Th2 ( $n=6)$. Lower panels: one representative FACS profile of Th2 and 4 $48 \mathrm{c}$-treated Th2 showing CDT1 and GEMININ expressing cells 


\section{Additional files}

Additional file 1: Supplementary figures S1-S11. (PDF 3129 kb)

Additional file 2: Table S1. List of differentially expressed genes upon IRE1a inhibition. (XLS 508 kb)

Additional file 3: Table S2. The list of XBP1 target genes and the genes that are potentially co-regulated by XBP1 and NF-Y. (XLSX 1208 kb)

Additional file 4: Table S3. List of XBP1 direct target genes as defined by its differential expression upon IRE1a inhibition (i.e., $4 \mu 8 \mathrm{c}$ treatment) and XBP1 occupancy at the gene locus. (XLSX 433 kb)

Additional file 5: Table S4. List of transcription factors that are direct targets of XBP1. (XLSX $16 \mathrm{~kb}$ )

Additional file 6: Table S5. List of differentially expressed genes that have annotated interactions with the target transcription factors in the STRING database. (XLSX $24 \mathrm{~kb}$ )

Additional file 7: Table S6. List of differentially expressed genes encoding both positive and negative regulators of cell proliferation. (XLSX $48 \mathrm{~kb})$

Additional file 8: Table S7. List of XBP1 direct target genes that regulate cell proliferation. (XLS $21 \mathrm{~kb}$ )

Additional file 9: Table S8. List of differentially expressed genes that regulate cell cycle. (XLSX $45 \mathrm{~kb}$ )

Additional file 10: Table S9. List of XBP1 direct target genes that regulate cell cycle. (XLS $17 \mathrm{~kb})$

\section{Abbreviations}

4H8c: 7-Hydroxy-4-methyl-2-oxo-2H-1-benzopyran-8-carboxaldehyde; ChIP: Chromatin immunoprecipitation; DC: Dendritic cell; ELISA: Enzymelinked immunosorbent assay; ER: Endoplasmic reticulum; FACS: Fluorescentactivated cell sorting; FUCCI mouse: Fluorescent ubiquitin cell cycle indicator mouse; IL: Interleukin; IRE1a: Inositol-requiring enzyme 1 alpha; Th: T helper; Th2: Type-2 T helper; UPR: Unfolded protein response; XBP1: X-box binding protein 1; XBP1s: Spliced form of X-box binding protein 1; XBP1U: Unspliced form of $X$-box binding protein 1

\section{Acknowledgements}

We would like to thank Helen E. Jolin for the technical help with in vivo experiments; Padraic Fallon for providing N. brasiliensis larvae; David Ron and Heather P. Harding for providing a plasmid vector of mouse XBP1s; Bee Ling $\mathrm{Ng}$, Chris Hall, and Jennie Graham for the help with flow cytometry; Kylie James for editing the manuscript; and Research Support Facility, WSI, for their technical help and animal husbandry.

\section{Funding}

This work was supported by European Research Council grant ThSWITCH (grant number: 260507) and ThDEFINE (Project ID: 646794). BM is funded by the CRUK Cancer Immunology fund (Ref. 20193), XC by the FET-OPEN grant MRG-GRAMMAR, and TG by the European Union's H2020 research and innovation programme "ENLIGHT-TEN" under the Marie Sklodowska-Curie grant agreement 675395. JH is funded by the Swedish Research Council.

\section{Availability of data and materials}

XBP1 ChIPseq datasets are available in the ArrayExpress E-MTAB-6327 (https://www.ebi.ac.uk/arrayexpress/experiments/E-MTAB-6327/). RNAseq datasets are available publicly in the ArrayExpress E-MTAB-6894 (https:// www.ebi.ac.uk/arrayexpress/experiments/E-MTAB-6894/) and E-MTAB-7104 (https://www.ebi.ac.uk/arrayexpress/experiments/E-MTAB-7104/).

Analyzed data can be browsed at http://data.teichlab.org.

\section{Authors' contributions}

JP designed, performed, and was involved in all the experiments; analyzed and interpreted the data; wrote the manuscript; and led this study. XC performed the ChIPmentation experiment, analyzed the data, and contributed to the manuscript writing. GK analyzed the RNA-seg data and ChIPmentation data. TG integrated ChIPmentation and RNAseq data to reveal transcriptional regulatory network and direct target genes. JH created the web browser to visualize the data. JEP was responsible for the sub-cloning of XBP1 expression vector. ZM analyzed the transcriptomic data. KN shared the FUCCI mouse and analyzed the cell cycle-associated genes. KM provided important feedback and critical comments during manuscript writing/editing and addressing reviewers' comments. ANJM conducted the Nippostrongylus infection experiments. BM raised the biological question, designed the experiments, helped in the data analysis and data interpretation, and wrote the manuscript. SAT generated the biological question/hypothesis, designed the experiments, and supervised the study. All authors read and approved the final manuscript.

\section{Ethics approval}

Animal research at WTSI and MRC-LMB was conducted under license from the UK Home Office (PPLH 70/7968 and 70/8381, respectively), and the institute's animal welfare and ethical review body approved the used protocols. All procedures were in accordance with the Animals (Scientific Procedures) Act 1986.

\section{Consent for publication}

Not applicable

\section{Competing interests}

The authors declare that they have no competing interests.

\section{Publisher's Note}

Springer Nature remains neutral with regard to jurisdictional claims in published maps and institutional affiliations.

\section{Author details}

${ }^{1}$ Wellcome Sanger Institute, Wellcome Genome Campus, Hinxton, Cambridge CB10 1SA, UK. ²EMBL-European Bioinformatics Institute, Wellcome Genome Campus, Hinxton, Cambridge CB10 1SD, UK. ${ }^{3}$ MRC Laboratory of Molecular Biology, Cambridge Biomedical Campus, Francis Crick Avenue, Cambridge CB2 0QH, UK. ${ }^{4}$ Theory of Condensed Matter, Cavendish Laboratory, $19 \mathrm{JJ}$ Thomson Ave, Cambridge CB3 OHE, UK.

Received: 14 June 2018 Accepted: 12 October 2018

Published online: 24 October 2018

\section{References}

1. Walker JA, McKenzie ANJ. TH2 cell development and function. Nat Rev Immunol. 2017;18:121-3.

2. Zhu J, Yamane H, Paul WE. Differentiation of effector CD4 T cell populations. Annu Rev Immunol. 2010;28:445-89.

3. Murphy KM, Reiner SL. The lineage decisions of helper T cells. Nat Rev Immunol. 2002;2:933-44

4. Wegmann TG, Lin H, Guilbert L, Mosmann TR. Bidirectional cytokine interactions in the maternal-fetal relationship: is successful pregnancy a $\mathrm{TH} 2$ phenomenon? Immunol Today. 1993:14:353-6.

5. Ellyard Jl, Simson L, Parish CR. Th2-mediated anti-tumour immunity: friend or foe? Tissue Antigens. 2007:70:1-11.

6. Gett AV, Hodgkin PD. Cell division regulates the T cell cytokine repertoire, revealing a mechanism underlying immune class regulation. Proc Natl Acad Sci U S A. 1998:95:9488-93.

7. Bird JJ, Brown DR, Mullen AC, Moskowitz NH, Mahowald MA, Sider JR, Gajewski TF, Wang CR, Reiner SL. Helper T cell differentiation is controlled by the cell cycle. Immunity. 1998;9:229-37.

8. Hosokawa H, Tanaka T, Kato M, Shinoda K, Tohyama H, Hanazawa A, Tamak Y, Hirahara K, Yagi R, Sakikawa I, et al. Gata3/Ruvbl2 complex regulates T helper 2 cell proliferation via repression of Cdkn2c expression. Proc Nat Acad Sci U S A. 2013;110:18626-31.

9. Hetz C. The unfolded protein response: controlling cell fate decisions under ER stress and beyond. Nat Rev Mol Cell Biol. 2012;13:89-102.

10. Calfon M, Zeng H, Urano F, Till JH, Hubbard SR, Harding HP, Clark SG, Ron D. IRE1 couples endoplasmic reticulum load to secretory capacity by processing the XBP-1 mRNA. Nature. 2002;415:92-6.

11. Frakes AE, Dillin A. The UPRER: sensor and coordinator of organismal homeostasis. Mol Cell. 2017;66:761-71.

12. Kaser A, Blumberg RS. Survive an innate immune response through XBP1. Cell Res. 2010;20:506-7.

13. Hetz C, Papa FR. The unfolded protein response and cell fate control. Mol Cell. 2017:69:169-81. 
14. Hetz C, Martinon F, Rodriguez D, Glimcher LH. The unfolded protein response: integrating stress signals through the stress sensor IRE1alpha. Physiol Rev. 2011;91:1219-43.

15. Acosta-Alvear D, Zhou Y, Blais A, Tsikitis M, Lents NH, Arias C, Lennon CJ, Kluger $Y$, Dynlacht BD. XBP1 controls diverse cell type- and conditionspecific transcriptional regulatory networks. Mol Cell. 2007;27:53-66.

16. Janssens S, Pulendran B, Lambrecht BN. Emerging functions of the unfolded protein response in immunity. Nat Immunol. 2014;15:910-9.

17. Brucklacher-Waldert V, Ferreira C, Stebegg M, Fesneau O, Innocentin S, Marie JC, Veldhoen M. Cellular stress in the context of an inflammatory environment supports TGF-beta-independent T helper-17 differentiation. Cell Rep. 2017;19:2357-70.

18. Bettigole SE, Glimcher LH. Endoplasmic reticulum stress in immunity. Annu Rev Immunol. 2015;33:107-38.

19. Grootjans J, Kaser A, Kaufman RJ, Blumberg RS. The unfolded protein response in immunity and inflammation. Nat Rev Immunol. 2016;16:469-84.

20. Hotamisligil GS. Endoplasmic reticulum stress and the inflammatory basis of metabolic disease. Cell. 2010;140:900-17.

21. Bettigole SE, Lis R, Adoro S, Lee AH, Spencer LA, Weller PF, Glimcher LH. The transcription factor XBP1 is selectively required for eosinophil differentiation. Nat Immunol. 2015;16:829-37.

22. Todd DJ, McHeyzer-Williams LJ, Kowal C, Lee AH, Volpe BT, Diamond B, McHeyzer-Williams MG, Glimcher LH. XBP1 governs late events in plasma cell differentiation and is not required for antigen-specific memory B cell development. J Exp Med. 2009;206:2151-9.

23. Iwakoshi NN, Pypaert M, Glimcher LH. The transcription factor XBP-1 is essential for the development and survival of dendritic cells. J Exp Med. 2007;204:2267-75

24. Brunsing R, Omori SA, Weber F, Bicknell A, Friend L, Rickert R, Niwa M. Band T-cell development both involve activity of the unfolded protein response pathway. J Biol Chem. 2008;283:17954-61.

25. Thaxton JE, Wallace C, Riesenberg B, Zhang Y, Paulos CM, Beeson CC, Liu B, Li Z. Modulation of endoplasmic reticulum stress controls CD4+ T-cell activation and antitumor function. Cancer Immunol Res. 2017;5:666-75.

26. Osorio F, Tavernier SJ, Hoffmann E, Saeys Y, Martens L, Vetters J, Delrue I, De Rycke R, Parthoens E, Pouliot P, et al. The unfolded-protein-response sensor IRE-1alpha regulates the function of CD8alpha+ dendritic cells. Nat Immunol. 2014;15:248-57.

27. Cubillos-Ruiz JR, Silberman PC, Rutkowski MR, Chopra S, Perales-Puchalt A, Song M, Zhang S, Bettigole SE, Gupta D, Holcomb K, et al. ER stress sensor XBP1 controls anti-tumor immunity by disrupting dendritic cell homeostasis. Cell. 2015;161:1527-38.

28. Shan B, Wang X, Wu Y, Xu C, Xia Z, Dai J, Shao M, Zhao F, He S, Yang L, et al. The metabolic ER stress sensor IRE1alpha suppresses alternative activation of macrophages and impairs energy expenditure in obesity. Nat Immunol. 2017;18:519-29.

29. Hetz C, Chevet E, Harding HP. Targeting the unfolded protein response in disease. Nat Rev Drug Discov. 2013;12:703-19.

30. Cubillos-Ruiz JR, Bettigole SE, Glimcher LH. Tumorigenic and immunosuppressive effects of endoplasmic reticulum stress in cancer. Cell. 2017:168:692-706.

31. Mort RL, Ford MJ, Sakaue-Sawano A, Lindstrom NO, Casadio A, Douglas AT, Keighren MA, Hohenstein P, Miyawaki A, Jackson IJ. Fucci2a: a bicistronic cell cycle reporter that allows Cre mediated tissue specific expression in mice. Cell Cycle. 2014;13:2681-96.

32. Mahata B, Zhang X, Kolodziejczyk AA, Proserpio V, Haim-Vilmovsky L, Taylor $A E$, Hebenstreit D, Dingler FA, Moignard V, Gottgens B, et al. Single-cell RNA sequencing reveals $T$ helper cells synthesizing steroids de novo to contribute to immune homeostasis. Cell Rep. 2014;7:1130-42.

33. Wu TD, Nacu S. Fast and SNP-tolerant detection of complex variants and splicing in short reads. Bioinformatics. 2010;26:873-81.

34. Anders S, Huber W. Differential expression analysis for sequence count data. Genome Biol. 2010;11:R106.

35. Schmidl C, Rendeiro AF, Sheffield NC, Bock C. ChIPmentation: fast, robust, lowinput ChIP-seq for histones and transcription factors. Nat Methods. 2015;12:963-5.

36. Zhang HM, Liu T, Liu CJ, Song S, Zhang X, Liu W, Jia H, Xue Y, Guo AY. AnimalTFDB 2.0: a resource for expression, prediction and functional study of animal transcription factors. Nucleic Acids Res. 2015;43:D76-81.

37. Szklarczyk D, Franceschini A, Wyder S, Forslund K, Heller D, Huerta-Cepas J, Simonovic M, Roth A, Santos A, Tsafou KP, et al. STRING v10: protein-protein interaction networks, integrated over the tree of life. Nucleic Acids Res. 2015:43:D447-52.

38. Naviaux RK, Costanzi E, Haas M, Verma IM. The $\mathrm{pCL}$ vector system: rapid production of helper-free, high-titer, recombinant retroviruses. J Virol. 1996; 70:5701-5.

39. Picelli S, Faridani OR, Bjorklund AK, Winberg G, Sagasser S, Sandberg R. Fulllength RNA-seq from single cells using Smart-seq2. Nat Protoc. 2014;9:171-81.

40. Cross BC, Bond PJ, Sadowski PG, Jha BK, Zak J, Goodman JM, Silverman RH, Neubert TA, Baxendale IR, Ron D, Harding HP. The molecular basis for selective inhibition of unconventional mRNA splicing by an IRE1-binding small molecule. Proc Natl Acad Sci U S A. 2012:109:E869-78.

41. Camberis M, Le Gros G, Urban J, Jr. Animal model of Nippostrongylus brasiliensis and Heligmosomoides polygyrus. Curr Protoc Immunol. 2003, Chapter 19:Unit 1912

42. Neill DR, Wong SH, Bellosi A, Flynn RJ, Daly M, Langford TK, Bucks C, Kane CM, Fallon PG, Pannell R, et al. Nuocytes represent a new innate effector leukocyte that mediates type-2 immunity. Nature. 2010;464:1367-70.

43. Zhang Y, Liu T, Meyer CA, Eeckhoute J, Johnson DS, Bernstein BE, Nusbaum C, Myers RM, Brown M, Li W, Liu XS. Model-based analysis of ChIP-Seq (MACS). Genome Biol. 2008:9:R137.

44. Quinlan AR, Hall IM. BEDTools: a flexible suite of utilities for comparing genomic features. Bioinformatics. 2010;26:841-2.

45. Heinz S, Benner C, Spann N, Bertolino E, Lin YC, Laslo P, Cheng JX, Murre C, Singh $\mathrm{H}$, Glass CK. Simple combinations of lineage-determining transcription factors prime cis-regulatory elements required for macrophage and B cell identities. Mol Cell. 2010:38:576-89.

46. Chen X, lliopoulos D, Zhang Q, Tang Q, Greenblatt MB, Hatziapostolou M, Lim E, Tam WL, Ni M, Chen Y, et al. XBP1 promotes triple-negative breast cancer by controlling the HIF1alpha pathway. Nature. 2014;508:103-7.

47. Mathelier A, Fornes O, Arenillas DJ, Chen CY, Denay G, Lee J, Shi W, Shyr C, Tan G, Worsley-Hunt R, et al. JASPAR 2016: a major expansion and update of the open-access database of transcription factor binding profiles. Nucleic Acids Res. 2016:44:D110-5.

48. Muller GA, Quaas M, Schumann M, Krause E, Padi M, Fischer M, Litovchick L, DeCaprio JA, Engeland K. The CHR promoter element controls cell cycledependent gene transcription and binds the DREAM and MMB complexes. Nucleic Acids Res. 2012:40:1561-78.

49. Chen X, Muller GA, Quaas M, Fischer M, Han N, Stutchbury B, Sharrocks AD, Engeland $\mathrm{K}$. The forkhead transcription factor FOXM1 controls cell cycledependent gene expression through an atypical chromatin binding mechanism. Mol Cell Biol. 2013;33:227-36.

50. McLean CY, Bristor D, Hiller M, Clarke SL, Schaar BT, Lowe CB, Wenger AM, Bejerano G. GREAT improves functional interpretation of cis-regulatory regions. Nat Biotechnol. 2010;28:495-501.

51. Hess DA, Strelau KM, Karki A, Jiang M, Azevedo-Pouly AC, Lee AH, Deering TG, Hoang CQ, MacDonald RJ, Konieczny SF. MIST1 links secretion and stress as both target and regulator of the UPR. Mol Cell Biol. 2016;36:2931-44.

52. Liang G, Audas TE, Li Y, Cockram GP, Dean JD, Martyn AC, Kokame K, Lu R. Luman/CREB3 induces transcription of the endoplasmic reticulum (ER) stress response protein Herp through an ER stress response element. Mol Cell Biol. 2006:26:7999-8010.

53. Santos A, Wernersson R, Jensen LJ. Cyclebase 3.0: a multi-organism database on cell-cycle regulation and phenotypes. Nucleic Acids Res. 2015; 43:D1140-4.

Ready to submit your research? Choose BMC and benefit from

- fast, convenient online submission

- thorough peer review by experienced researchers in your field

- rapid publication on acceptance

- support for research data, including large and complex data types

- gold Open Access which fosters wider collaboration and increased citations

- maximum visibility for your research: over $100 \mathrm{M}$ website views per year

At BMC, research is always in progress.

Learn more biomedcentral.com/submissions 